\title{
MÁS PERMANENCIAS QUE CAMBIOS EN EL MAPA POLÍTICO RISARALDENSE. Elecciones 2006 y 2007.
}

\section{PERMANENCY MORE THAN REAL CHANGES IN THE POLITICAL MAP IN RISARALDA. 2006 AND 2007 ELECTIONS.}

Oscar Arango Gaviria ${ }^{1}$

\begin{abstract}
This paper attempts to make a reflection on the electoral results in Risaralda State and to review the political changes in the electoral map. An the outline of the current political map and the distribution of the Colombian Congress, state assembly, municipal and local administrative councils is also advanced.

Furthermore, the electoral results from the presidential elections and the origin of political support are analyzed. An analysis of the parapolitics phenomena in Risaralda is reviewed.
\end{abstract}

\section{Resumen.}

Este artículo se encarga de realizar una reflexión sobre los resultados electorales en el departamento de Risaralda y revisa los cambios políticos en el mapa electoral, de igual manera, avanza en la reseña del actual mapa político y la configuración del Congreso de la República, la Asamblea Departamental, los Concejos Municipales y las Juntas Administradoras Locales.

En el mismo sentido, analiza los resultados electorales de las elecciones a presidente y los apoyos políticos recibidos; el análisis le pasa revista a los fenómenos de la parapolítica en el departamento de Risaralda.

\section{ELECCIONES DE CONGRESO.}

En las elecciones parlamentarias de 2006 estaban en juego al menos tres grandes decisiones: la conformación de un nuevo mapa de partidos; la fuerza y la vigencia de las colectividades históricas más grandes (Partido Liberal y Conservador), y el pulso entre las bancadas que apoyaban a Uribe y las de oposición. Pero, en general, la campaña giró en torno a este último punto: quién estaba con Uribe y quién no.

En todo caso, los debates programático partidistas quedaron eclipsados por las discusiones sobre las reglas la mecánica y por los escándalos sobre vínculos de candidatos con el paramilitarismo.

\section{RESULTADOS ELECTORALES PARA SENADO. ${ }^{2}$}

\footnotetext{
${ }^{1}$ Profesor, Universidad Tecnológica de Pereira. Coordinador Comité Técnico Red de Universidades Públicas del Eje Cafetero, Alma Mater. Las reflexiones aquí consignadas hacen parte de los trabajos investigativos del Grupo: Gestión Ambiental Territorial, en la línea de investigación: Ordenamiento ambiental del territorio y gobernabilidad democrática.
} 
Tanto en 2202, como en 2006 Risaralda participó con el 2\% del total de votos al Senado. Cifra que en alguna forma se compadece con el peso específico de la población departamental en el total nacional.

Sobresalió la votación que terminó siendo anulada. En 2006 fueron nulos el 10\% de los votos en todo el país y el 12\% de los votos en Risaralda, cuando en 2002 estos datos habían sido 3\% y $5 \%$ respectivamente.

Tabla 1. Colombia y Risaralda. Síntesis electoral para Senado. 2002-2006.

\begin{tabular}{|l|r|r|}
\hline \multirow{2}{*}{ INDICADOR } & \multicolumn{2}{|c|}{ SENADO } \\
\cline { 2 - 3 } & 2002 & \multicolumn{1}{|c|}{ 2006 $^{*}$} \\
\hline COLOMBIA & 10.297 .405 & $10,780,668$ \\
\hline Total votos & 3 & 10 \\
\hline Votos nulos \% & 6 & 3 \\
\hline Tarjetas no marcadas \% & 4 & 3 \\
\hline Votos en blanco \% & 58 & 60 \\
\hline$\%$ abstención & & 187,808 \\
\hline Umbral para Senado & & 82.112 \\
\hline Cifra repartidora & & 253,257 \\
\hline RISARALDA & 5 & 12 \\
\hline Total votos & 7 & 4 \\
\hline Votos nulos \% & 7 & 3 \\
\hline Tarjetas no marcadas \% & 57 & 58 \\
\hline Votos en blanco \% & & \\
\hline$\%$ abstención \% & & \\
\hline
\end{tabular}

El fenómeno de la abstención electoral en los comicios del Congreso sigue siendo preocupante: sólo participan efectivamente 42 de cada 100 ciudadanos. Una cifra que siempre deja una sombra de duda sobre la necesaria confianza en el poder legislativo.

El umbral, es decir, el límite a partir del cual los partidos compiten por las curules, fue de casi 189 mil votos $^{3}$, mientras que la cifra repartidora (el dato que permite identificar el número de curules efectivas a asignar a cada partido) fue de 82 mil votos.

Mientras en 2002 el Partido Liberal había elegido los tres candidatos que inscribió utilizando el mecanismo de la tristemente célebre operación avispa ${ }^{4}$, en el 2006 sólo obtuvo uno en el escenario de la lista única y el voto preferente. Lo ocurrido es consecuencia de diferentes factores: por una parte, Rodrigo Rivera, quien había conseguido en 2002 más de 30 mil votos, no se inscribió como aspirante al Senado para pasar a postularse como precandidato presidencial; por la otra, Maria Isabel Mejía, quien había obtenido casi 39 mil sufragios, y quien por más de 30 años militó en el liberalismo, y quien había sido sancionada por apoyar la candidatura de Álvaro Uribe en 2002, en el 2006 se sumó al partido de la U. De igual manera,

\footnotetext{
${ }^{2}$ Una evaluación nacional de este proceso se lee en RODRIGUEZ, Clara Rocío. Reforma política y elecciones parlamentarias: la evidencia de una nueva agenda. En revista Foro. No. 58, agosto, 2006. pp. 19-28

${ }^{3}$ Las autoridades electorales establecieron que el umbral se debía calcular sumando sólo los votos válidos por partidos y los votos en blanco, y no como se había solicitado, contabilizando la totalidad de la votación. De ser así, el umbral en 2006 habría subido a 215.558 votos.

${ }^{4}$ Mecanismo que le permitía a cada candidato encabezar su propia lista y a todos utilizar la misma personería del respectivo partido político. En 2002 hubo más de 300 listas al Senado.
} 
Habib Merheg que había llegado sorpresivamente al Senado en 2002 con el aval del partido Liberal sin previo recorrido electoral, debió soportar un descenso en su electorado al pasar de casi 39 mil votos en 2002 a 33 mil en el 2006.

La campaña estuvo cruzada por la presencia de candidatos con presuntos nexos con paramilitares. Según la revista Semana (25/01/06) "Juan Manuel Santos (jefe de la U) y Germán Vargas (jefe de Cambio Radical) decidieron expulsar de sus listas a cinco aspirantes: Jorge Castro, Luis Eduardo Vives, Jorge Caballero, Dief Maloof y Habib Merheg. Los primeros cuatro, todos de Magdalena, fueron vetados por haber participado en una reunión en una finca de Cesar con el comandante paramilitar 'Jorge 40'.

"El último vetado, Merheg, salió por los insistentes rumores que los vinculan con otro comandante paramilitar, alias 'Macaco', bajo cuya égida se movieron muchos hilos de la política en Risaralda.

"¿Qué hay detrás de todo este escándalo ¿Existen sólo rumores? ¿Hay indicios razonables? ¿Saldrán pruebas?" Se preguntó la revista. Al momento de escribir estas notas, prácticamente todos los señalados habían sido investigados por la Corte y varios de ellos están condenados.

Para la columnista Maria Teresa Ronderos, "la salida de Merheg fue otro mensaje hacia otro paramilitar: 'Si no juegas conmigo, no te dejo jugar'. Al parecer algunos beneficiados de Ralito no estaban tan convencidos de apoyar a Uribe en su reelección". En todo caso, quedó en claro que los organismos de control no contaban con métodos eficaces para evitar la infiltración de grupos ilegales.

EI PDA sumó en su lista de Senado el nombre de la dirigente risaraldense Gloria Inés Ramírez, postulación que salió airosa al conseguir el apoyo total de un poco más de 31 mil electores en el país ${ }^{5}$.

En 2006 el 14\% de los electores de Gloria Inés Ramírez; el 45\% del senador Merheg y el 77\% de Germán Aguirre fueron de Risaralda. En el primer caso, la explicación puede obedecer a que se trata de una dirigente que venía de ser Presidente de la Federación Colombiana de Educadores; en el caso de Merheg por sus influencias en el norte del Valle. El senador Aguirre siguió anclado fundamentalmente a los electores risaraldenses.

Tabla 2. Risaralda. Votación por senadores electos, según partido. 2002-2006

\begin{tabular}{|c|c|c|c|c|c|c|}
\hline \multirow[t]{2}{*}{ Candidato } & \multicolumn{2}{|c|}{ Votos 2002} & \multirow[t]{2}{*}{ Partido } & \multicolumn{2}{|c|}{ Votos 2006} & \multirow[t]{2}{*}{ Partido } \\
\hline & En Risaralda & Total & & $\begin{array}{c}\text { En } \\
\text { Risaralda }\end{array}$ & Total & \\
\hline Maria I. Mejía & 38.797 & 55.087 & Liberal & & & \\
\hline Rodrigo Rivera & 31.348 & 72.612 & Liberal & & & \\
\hline Habib Merheg & 38.666 & 60.330 & Liberal & 25,169 & 46,045 & $\begin{array}{l}\text { Colombia } \\
\text { Viva } \\
\end{array}$ \\
\hline Germán Aguirre & & & & 32,909 & 42,716 & Liberal \\
\hline Gloria I. Ramírez & & & & 4,385 & 31,376 & PDA \\
\hline
\end{tabular}

${ }^{5}$ La lista de Senado del PDA sumó en Risaralda 13.576 votos. Además de lo conseguido por la Senadora Ramírez, se obtuvo un apreciable apoyo a las aspiraciones de Jorge Robledo, Gustavo Petro y Guillermo A. Jaramillo. 
Fuente: con base en Registraduría Nacional

Se presumía que mientras el senador Merheg haría parte de la bancada uribista, los senadores Ramírez y Aguirre estarían, con el PDA y el Partido Liberal, en la oposición.

Aunque no salió electa, debe recordarse el caso de la exgobernadora Elsa Gladys Cifuentes. Ella venía de la Nueva Fuerza Democrática y su elección a la Gobernación -con la votación más alta hasta ese momento- se apoyó en el denominado Pacto de Guacari ${ }^{6}$. En 2006 tramitó su aspiración al Senado liderando en Risaralda el movimiento Cambio Radical ${ }^{7}$. Su votación sumó 18 mil electores en todo el país (11 mil en Risaralda). En desarrollo del proceso de la parapolítica y por el llamado a juicio de varios de los senadores de Cambio Radical, en 2008 se posesiona como Senadora.

Tabla 3. Risaralda. Votación para Senado según partido. 2006

\begin{tabular}{|c|c|c|}
\hline PARTIDO & VOTOS & \% DEPTAL \\
\hline De la U. & 37,439 & 19 \\
\hline Conservador & 28,715 & 14 \\
\hline Cambio Radical & 18.033 & 9 \\
\hline Convergencia Ciudadana & 2,341 & 1 \\
\hline Alas Equipo Colombia & 865 & 0,5 \\
\hline Colombia Democrática & 1,301 & 1 \\
\hline Colombia Viva & 30,292 & 15 \\
\hline Votación partidos uribistas & 118.986 & 60 \\
\hline Liberal & 52,876 & 27 \\
\hline PDA & 13,576 & 6 \\
\hline Votación liberal y del PDA & 66.452 & 33 \\
\hline MIRA & 12,414 & 7 \\
\hline C4 & 3. 009 & 1.5 \\
\hline
\end{tabular}

Fuente: con base en Registraduría Nacional del Estado Civil

Por último está el caso del exrepresentante Juan Hurtado. Sus electores no alcanzaron a 17 mil en Colombia (un poco más de 14 mil en Risaralda). Probablemente en compensación, el Presidente Uribe, lo nombró en la representación diplomática de Colombia en Israel.

\section{RESULTADOS ELECTORALES PARA CAMARA DE REPRESENTANTES}

Sorprendió que ni Cambio Radical ni Colombia Viva presentaran listas para Cámara, pues entre ambas organizaciones obtuvieron en Risaralda casi 37 mil votos para Senado.

Tabla 4. Risaralda. Listas a la Cámara, según partido. 2006

\footnotetext{
${ }^{6}$ Un pacto que agrupó a la congresista liberal Maria Isabel Mejía, a otro sector del Partido Liberal encabezado por el exrepresentante Octavio Carmona-, a la Nueva Fuerza Democrática, al Partido Conservador y otros grupos menores, contra el grupo liberal que en Risaralda encabezaba en ese momento Rodrigo Rivera. Finalmente el pacto salió adelante y gobernó en Risaralda con Elsa Gladis Cifuentes y en la alcaldía de Pereira con Martha Elena Bedoya.

${ }^{7}$ Curiosamente, este movimiento no presentó lista para Cámara de Representantes.
} 


\begin{tabular}{|llll|}
\hline \multicolumn{1}{|c}{ Liberal } & \multicolumn{1}{c}{ Conservador } & \multicolumn{1}{c|}{ De la U } & \multicolumn{1}{c|}{ PDA } \\
\hline Diego Patiño & Diego Naranjo & Adriana Vallejo & Gonzalo Arango \\
Juan C. Valencia & Luis C. Ramírez & Carlos E. Soto & Vicente Villada \\
Ernesto Zuluaga & Ramiro Velásquez & John J. Velásquez & Marino Alzate \\
Carlos Crostwaithe & Amparo L. Vega & Edgar Saldarriaga & Henry Cuervo \\
& & \multicolumn{1}{c}{ C4 } & \\
\multicolumn{1}{|c|}{ MIRA } & OPCION CENTRO & \multicolumn{1}{c}{} \\
Patricia Velásquez & Ricardo Martínez & Jesús Romero & \\
Cesar A. García & Pablo Loaiza & Carlos A Quiroz & \\
Giomar Vélez & Guillermo Botero & Gustavo Tamayo & \\
Andrés F. Ocampo & Luis Bustamante & John Londoño & \\
\hline
\end{tabular}

Se obtuvo la efectiva participación del $40 \%$. Cuatro años antes había participado el $43 \%$. El umbral sumó 23.729 sufragios (50\% del cuociente electoral). La cifra repartidora cerró en 33.156 votos. Entre los votos nulos (39.275), las tarjetas no marcadas (11.774) y los votos en blanco (6.649) sumaron 60 mil los sufragios que no participaron directamente de la elección real de los representantes. Esto significa el $23 \%$ sobre los 241 mil votos depositados.

En cuanto a los resultados políticos también hubo interesantes modificaciones en el mapa político risaraldense.

De los cuatro representantes a los que tenía derecho Risaralda en esta oportunidad, dos fueron 'nuevos' y repitieron curul Carlos E. Soto y Diego Patiño.

Tabla 5. Risaralda. Representantes electos, según partido. 2002-2006

\begin{tabular}{|c|c|c|c|c|}
\hline \multirow[t]{2}{*}{ Candidato } & \multicolumn{2}{|c|}{2002} & \multicolumn{2}{|c|}{2006} \\
\hline & Partido & Votos & Partido & Votos \\
\hline Juan Carlos Valencia & & & Liberal & 28480 \\
\hline Diego Patiño & & & Liberal & 27125 \\
\hline Carlos Enrique Soto & Liberal & 32523 & De la U & 20717 \\
\hline Diego Naranjo & & & Conservador & 8772 \\
\hline Germán Aguirre & Liberal & 28277 & & \\
\hline John Jairo Velásquez & Liberal & 24598 & & \\
\hline $\begin{array}{l}\text { Juan Hurtado } \\
\text { Fuente: con base en } \mathrm{F}\end{array}$ & $\begin{array}{l}\text { Conservador } \\
\text { ría del Estado C }\end{array}$ & 21091 & & \\
\hline
\end{tabular}

El partido Liberal pasó de tres a dos Representantes. En el período 2002-2006 descendió de 80 mil a 69 mil electores. La explicación fundamental se ubica en el comportamiento de los representantes Carlos Soto, quien abandonó las filas del liberalismo desde 2002, pasó a apoyar el Nuevo Partido y, con éste, se sumó luego al Partido de la U. Lo propio hicieron el exrepresentante John Jairo Velásquez ${ }^{8}$ y Adriana Vallejo ${ }^{9}$ desde el liberalismo hacia el Partido de la U.

${ }^{8}$ En 2002 había salido Representante con el apoyo del movimiento Alternativa Liberal que orienta Octavio Carmona, un exrepresentante que por las sanciones penales de las que fue objeto no pudo volver a aspirar a cargos de elección popular.

${ }^{9}$ En esta, que era su primera incursión electoral, obtuvo un poco más de 11 mil votos. 
Por el lado conservador también hubo cambios de interés. Se disminuyó de 39 mil a 33 mil electores. En 2002 se había elegido a Juan Hurtado. La lista de Cámara incluyó los nombres de Luis Carlos Ramírez (copropietario del periódico Diario del Otún), Amparo Lucía Vega (exgobernadora de Risaralda), Ramiro Velásquez (empresario) y Diego Naranjo, quien venía de ser alcalde de Belén de Umbría.

La sorpresa fue evidente: el electorado conservador se inclinó por el nombre de Diego Naranjo quien consiguió su curul con menos de 9 mil votos y su elección dejó más lastimada la unidad política real del partido Conservador en el departamento, pues su liderazgo ya encuentra serias resistencias por parte de quienes no admiten que los cargos de representación queden en manos de un 'dirigente de provincia'.

La lista del PDA, sumó 8.241 votos, 4.650 menos que los obtenidos en la lista de Senado, y 6.718 menos de los que se depositaron en la consulta para definir candidatura presidencial, lo cual confirma que también en Risaralda esta agrupación presenta notables distancias considerables entre la dinámica nacional y el alcance de su inserción regional.

Aunque no consiguió curul el MIRA continuó incrementando su influencia política y pasó de 9 mil a 13 mil electores. En esta elección el 43\% de los votos optaron por Patricia Velásquez, quien lleva la vocería del movimiento en Risaralda.

También figuró en el tarjetón de aspirantes a la Cámara el movimiento Opción Centro, disputando la curul especial de minorías políticas. Esta agrupación mantuvo un acuerdo electoral con Convergencia Ciudadana y consiguió 4.130 votos, de los cuales casi el $70 \%$ fueron depositados por el dirigente santarrosano Ricardo Martínez.

Por su parte, se depositaron 2.358 sufragios para participar de la curul especial de Cámara asignada a las comunidades indígenas. La mayor representación la consiguió la Alianza Social Indígena. Los votos en blanco para esta circunscripción sumaron 2.059, casi tantos como los anteriores.

En cuanto a la disputa por la curul especial para las comunidades afrocolombianas, se aportaron un poco más de dos mil votos, siendo la propuesta del movimiento Cimarrón la de mayor acogida relativa.

El $20 \%$ de los votos en el caso del PDA, el $19 \%$ en el caso del MIRA y el $18 \%$ en el del Partido de la $U$ fueron depositados para favorecer la lista en su conjunto. En pequeña escala, este puede ser un buen indicio para seguir alimentando la discusión a favor de quienes consideran incoherente la simultaneidad de lista única y voto preferente. En los casos de los partidos Liberal y Conservador, la cifra de apoyo a la lista fue del $7 \%$.

En resumen, para la Cámara se eligieron dos candidatos del liberalismo, uno del Partido de la U y uno del Partido Conservador, es decir, una especie de suma cero al momento de cuantificar apoyos y oposición a las iniciativas legislativas gubernamentales.

\section{ELECCION PRESIDENCIAL EN RISARALDA.}

La campaña de 2006 fue sui géneris porque: a) Operaba a nivel nacional la reforma política de 2003; b) Se estrenaba la figura de la reelección presidencial y, c) Se mantenían las tensiones propias de la participación en política de los grupos paramilitares así como la presión armada de las guerrillas. 
Dado que en Colombia quien gana las elecciones es a la vez jefe de Estado y jefe de Gobierno, o mejor, quien triunfa 'gana todo', la presencia de un Presidente-candidato propició una campaña sin antecedentes.

En 2002 Álvaro Uribe había triunfado sobre Horacio Serpa superándolo por más de 2.3 millones de votos. En Risaralda, Uribe consiguió 191 mil votos, el $70 \%$ del total departamental. Serpa obtuvo 39 mil sufragios (14\%), Noemí Sanin, a nombre del Movimiento Sí Colombia, sumó 17.552 electores (6\%) y Luis Eduardo Garzón, el candidato del Frente Social y Político, acumuló casi 15 mil votos (5\%).

En 2006 se configuraron tres grandes corrientes de opinión política. En la primera, los partidos afectos al uribismo volvieron a agruparse y, ahora con la motivación de un Presidente candidato, por una parte, y con un triunfo que superó sus propios cálculos en las elecciones de Congreso, por la otra, pudieron aplazar sus evidentes diferencias y trabajar bajo la coordinación de Primero Colombia, un instrumento ad hoc que ya había prestado con éxito sus servicios en 2002.

En la segunda, estuvieron los partidarios de la candidatura de Carlos Gaviria, que venían motivados por una decorosa presentación de sus listas al Congreso en las elecciones de marzo (sumaron 9 Senadores y 11 Representantes). La particularidad era que muchos de los simpatizantes de esta opción no militaban en las filas del Polo Democrático Alternativo -PDA.

En tercer lugar, se agruparon los electores leales a la tercera candidatura de Horacio Serpa, muchos de los cuales se presumen afiliados al Partido Liberal. En su caso, tenían que superar la falta de incentivos que les había dejado su participación en la campaña de Congreso y las fracturas políticas derivadas de la consulta presidencial interna.

Uribe había llegado a la Presidencia en 2002 sin partido propio y descartando apoyos, porque los consideraba "corruptos y politiqueros". En 2006 propició que varias organizaciones partidistas auspiciaran su reelección, incluyendo los grupos que durante la campaña de Congreso habían sido rechazados: Colombia Viva y Convergencia Ciudadana.

Estas elecciones tuvieron un contexto que fue calificado como el proceso menos violento de los últimos nueve años ${ }^{10}$. En Pereira se presentó un hostigamiento con explosivos en la sede del movimiento Primero Colombia sin que se reportaran víctimas. También ocurrió el intento de secuestro y el homicidio de Liliana Gaviria, hermana del expresidente Cesar Gaviria. La familia Gaviria es oriunda de esta ciudad. Las personas detenidas y condenadas por el homicidio reconocieron haberlo hecho como parte de una de las acciones de las FARC.

En Risaralda la coordinación de la campaña estuvo a cargo de excandidatos al Senado (Elsa Gladys Cifuentes, Maria Isabel Mejía y Juan Hurtado) y a la Cámara (Adriana Vallejo), los Representantes Diego Naranjo y Carlos Enrique Soto, los empresarios Eric Drews y Arturo Vallejo, entre otros. Los lineamientos estratégicos fueron los mismos en todo el país.

Esta manera de enfrentar la campaña permitió la 'unidad' alrededor de la candidatura de Uribe sin que fuera necesario disolver las estructuras organizativas de los partidos; además, se presentó una candidatura inscrita por firmas, es decir, con respaldo suprapartidista. Desde la dirección publicitaria se acuñó el slogan Adelante Presidente, queriendo indicar que el Presidente sólo estaba atendiendo un clamor generalizado.

${ }^{10}$ Fundación Seguridad y Democracia. Violencia política en los procesos electorales. Bogotá, 2006 
Se volvió a priorizar el tema de la denominada seguridad democrática. Contrario a lo que habían hecho en otros comicios las FARC no desplegaron sus acostumbradas ofensivas armadas; el proceso de acercamiento con el ELN continuaba discretamente su marcha y los inconvenientes políticos derivados de la aplicación de la ley de justicia y paz a los grupos paramilitares desmovilizados, dejaban en la opinión un sabor agridulce. El país mantuvo abierta la discusión a propósito del eventual acuerdo humanitario. Como era previsible, el proceso de desmovilización también se mantuvo entre los asuntos de interés para todas las campañas presidenciales. También se recurrió al deslinde ideológico para consolidar apoyos electorales. "El país tendrá que escoger si sigue por el mejoramiento de la seguridad democrática como camino a la paz o retrocede para que el comunismo disfrazado le entregue el país a las Farc", dijo el Presidente candidato ${ }^{11}$.

El proceso alrededor de la eventual firma del Tratado de Libre Comercio con los Estados Unidos volvió a erigirse como tema central de campaña. Álvaro Uribe hizo del TLC su principal bandera económica y las candidaturas de Carlos Gaviria y de Horacio Serpa se declararon abiertamente en contra del tratado.

Mapa 1. Municipios en los cuales la suma de los votos de Horacio Serpa y Nohemí Sanin fue superior con respecto a los $51 \%$ a los de Álvaro Uribe.

${ }^{11}$ El Espectador. 27/05/06 


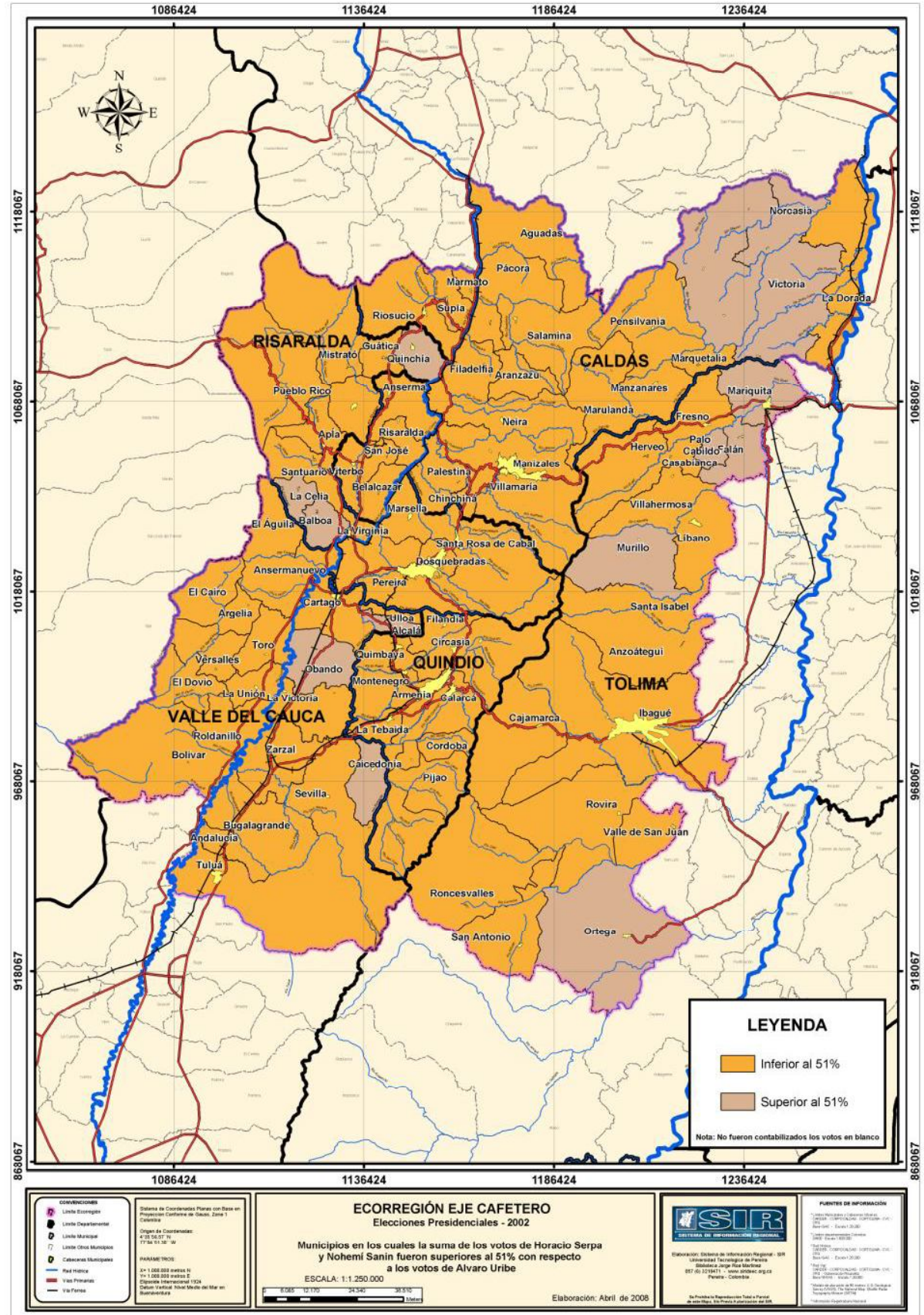

\section{Consultas internas para la selección de candidatos.}

El partido Conservador realizó a fines de 2005 una consulta popular para definir si tenían candidato presidencial propio o respaldaban la reelección de Álvaro Uribe. Esta última opción se impuso con un poco más del $90 \%$ del millón de votos conseguidos.

Tras ganar la consulta interna del partido Liberal y cargando a cuestas la cruz que para su imagen significó haber aceptado la embajada del gobierno Uribe en la OEA y con una votación 
cercana al millón de votos, Horacio Serpa debió enfrentarse a Rafael Pardo, Rodrigo Rivera y Andrés González. La participación total en la consulta liberal superó los 2.7 millones de votos. Serpa nombró como fórmula vicepresidencial a Iván Marulanda, un dirigente oriundo de Pereira, exalcalde de esta ciudad, exsenador por el Nuevo Liberalismo y exconsituyente,

En Risaralda, con excepción del grupo de Alternativa Liberal, quien hizo campaña a favor de Serpa, los demás dirigentes liberales se alinearon con la precandidatura de Rodrigo Rivera, un exsenador pereirano que hizo su carrera política en estas tierras. En temas como el TLC se mostró bastante conciliador y en asuntos como los derechos de homosexuales, aborto o educación religiosa, su postura fue conservadora. Obtuvo 41 mil votos, mientras que Serpa no alcanzó los 9 mil electores y Rafael Pardo se aproximó a los 8 mil sufragios.

EI PDA también utilizó el expediente de la consulta interna para seleccionar su candidato presidencial y consiguió que un poco más de un millón de electores acudieran a las urnas, cifra sin antecedentes en las organizaciones de izquierda en el país. En Risaralda sumaron 11.385 mil votos a favor de Carlos Gaviria y 4.259 mil votos por la candidatura de Antonio Navarro. Los electores del Polo en esta consulta interna aportaron sólo el 1.5\% del total nacional.

Contrario a lo ocurrido en las elecciones de marzo para conformar el Congreso ${ }^{12}$, en esta ocasión hubo un acierto generalizado de las encuestas. El candidato Presidente nunca estuvo por debajo del $50 \%$ en la intención del voto. Las encuestas también coincidieron en pronosticar que Carlos Gaviria sería el fenómeno político de la campaña. Su índice de favorabilidad política más que se duplicó en tres meses y pudo superar las intenciones de voto por Serpa.

\section{RESULTADOS ELECTORALES.}

A nivel nacional, las elecciones presidenciales de 2006 superaron levemente los 12 millones de votos, pero la abstención subió de $54 \%$ a 55\%. En Risaralda la abstención se mantuvo en 51\%, habiéndose pasado de 277 mil sufragios en 2002 a 296 mil votos.

Tabla 6. Indicadores de elecciones Presidenciales y de Senado. 2002-2006

\begin{tabular}{|c|c|c|c|c|}
\hline \multirow[t]{2}{*}{ Indicador } & \multicolumn{2}{|c|}{ Senado } & \multicolumn{2}{|c|}{ Presidente } \\
\hline & 2002 & $2006^{*}$ & 2002 & 2006 \\
\hline \multicolumn{5}{|l|}{ Colombia } \\
\hline Total votos & 10.297 .405 & $10,780,668$ & 11.249 .734 & $12,058,788$ \\
\hline Votos nulos & 355.070 & $1,053,721$ & 149.123 & 136,326 \\
\hline Tarjetas sin marcar & 656.158 & 336,539 & 48.966 & 84,041 \\
\hline Votos en blanco & 454.740 & 272,645 & 196.116 & 230,749 \\
\hline Votos válidos & 9.286 .175 & $9,390,408$ & 11.051 .645 & $11,838,421$ \\
\hline \% abstención & 58 & 60 & 54 & 55 \\
\hline \multicolumn{5}{|l|}{ Risaralda } \\
\hline Total votos & 237.983 & 253,257 & 277.203 & 296,582 \\
\hline Votos nulos & 10.179 & 29,576 & 5.067 & 4,554 \\
\hline Tarjetas sin marcar & 17.134 & 9,374 & 1.173 & 1,915 \\
\hline Votos en blanco & 10.179 & 6,905 & 5.033 & 6,562 \\
\hline
\end{tabular}

${ }^{12}$ El Tiempo, por ejemplo, anunciaba que el triunfador en la jornada sería el Partido Liberal que conseguiría 27 curules en el Senado y que el Partido de la U compartiría el tercer lugar al lado de Cambio Radical y del PDA, cada uno con doce Senadores. 


\begin{tabular}{lrrrr} 
Votos válidos & 208.076 & 214,307 & 270.963 & 290,113 \\
$\%$ abstención & 57 & 58 & 50 & 51 \\
\hline Fuente: con base en Registraduría Nacional del Estado Civil & &
\end{tabular}

Una vez más, la participación electoral en las jornadas presidenciales fue superior a la registrada en los comicios para Senado.

\section{La votación por Álvaro Uribe.}

Rompiendo la historia, en 2006 Álvaro Uribe fue reelegido en primera vuelta y consiguió la mayor votación (7.4 millones de votos) para las elecciones presidenciales, superando su propio registro (5.9 millones de votos) en 2002 y pasando por encima de los 6 millones de sufragios depositados en la segunda vuelta presidencial que terminó eligiendo a Andrés Pastrana en 1998.

En Risaralda, Álvaro Uribe había conseguido 191 mil votos en 2002 y pasó a casi 211 mil en 2006 que es, de lejos, la mayor cifra obtenida por un candidato presidencial en este territorio.

Tabla 7. Colombia y Risaralda. Síntesis de elecciones presidenciales. 2002-2006

\begin{tabular}{|lll|}
\hline \multicolumn{1}{|c|}{ Presidente } & \multicolumn{1}{c|}{ 2a votación } & \multicolumn{1}{c|}{ Otros candidatos } \\
\hline $\mathbf{2 0 0 2}$ & & \\
Total país & & \\
Álvaro Uribe & Horacio Serpa & Luis E. Garzón, Noemí Sanín, Ingrid Betancur \\
5,862,655 & $3,524,779$ & \\
Total Risaralda & & \\
Álvaro Uribe & Horacio Serpa & Nohemí Sanin (17.148) \\
191.141 & 39.088 & Luis E. Garzón $(14.784)$ \\
$\mathbf{2 0 0 6}$ & & \\
Total país & & \\
Álvaro Uribe & Carlos Gaviria & Horacio Serpa \\
7,397,835 & $2,613,157$ & $1,404,235$ \\
Total Risaralda & & \\
Álvaro Uribe & Carlos Gaviria & Horacio Serpa \\
210,738 & 47,663 & 20,418 \\
\hline
\end{tabular}

Fuente: con base en Registraduría Nacional del Estado Civil

Ahora bien, en medio de los serios cuestionamientos acerca de un eventual regreso al uribismo por parte de los dirigentes expulsados en enero de 2006, y con el propósito de facilitar acercamientos, el Presidente candidato había invitado a "todos los partidos y movimientos a respaldar su candidatura", lo cual obviamente incluía un llamado al senador risaraldense Habib Merheg quien, según se explicó atrás, había sido excluido del Partido de la U y, quizás contra su voluntad, se había visto forzado a recomponer el movimiento Colombia Viva al cual los observadores ya le tenían certificado de defunción, pues sus demás dirigentes también se habían matriculado en el Partido de la U .

Frente a la campaña presidencial, Merheg mantuvo curiosas posiciones. Había sido pública su oposición al TLC con los EE.UU. y mantuvo declaraciones en contra de la propuesta de reforma tributaria y de la iniciativa gubernamental destinada a recortar la participación de las entidades territoriales ordenada en la Constitución Política. No obstante, persistió en su adhesión a la 
campaña de Uribe porque, según sus declaraciones, compartía con ella los principios generales de "seguridad, orden y libertad". De cualquier manera, con posterioridad a las elecciones presidenciales y en virtud de acuerdos políticos de la coalición uribista, este senador ${ }^{13}$ volvió a participar de de la coalición oficial y fue nombrado vicepresidente de la comisión sexta.

Ahora bien, la desagregación de la votación por municipios en Risaralda deja ver procesos políticos de importancia. Para empezar, aquellas localidades en las que Uribe alcanzó más del $75 \%$ del total de electores. Este es el caso de Apia (81\%), Belén (78\%), La Celia (78\%), Santa Rosa (78\%) y Santuario (75\%). Estos cinco municipios han tenido importantes votaciones conservadoras, aunque en La Celia se han presentado coaliciones supra partidistas a la alcaldía y en Santa Rosa, el exalcalde Carlos Toro fue inscrito con firmas de ciudadanos y elegido en 2003 en virtud de una coalición suprapartidista.

Luego están los municipios que ofrecieron al Presidente candidato entre el 60 y el $75 \%$ de apoyo: Guática (74\%), Dosquebradas (72\%), Marsella (69\%), Pereira (66\%) y La Virginia (64\%). Con excepción de Guática, municipio de gran tradición electoral conservadora, en este segundo grupo se ubican los municipios metropolitanos y, en particular, Pereira, la ciudad capital. Todos ellos tienen por característica una activa presencia histórica del Partido Liberal.

En tercer lugar aparecen las localidades en las que el respaldo a la candidatura de Álvaro Uribe osciló entre el $50 \%$ y el $60 \%$ de los ciudadanos que acudieron a las urnas. En este grupo están Pueblo Rico y Mistrató con 55\% cada uno, y Balboa (50\%). Los dos primeros son municipios de importante presencia de comunidades indígenas y afro colombianas, lo mismo que del conflicto armado en la última década. Balboa es un pequeño municipio donde el liberalismo ha ejercido un histórico control sobre el Concejo y la Alcaldía.

Tabla 8. Risaralda. Elección presidencial según candidato, por municipio. 2002-2006.

\begin{tabular}{|c|c|c|c|c|c|c|}
\hline \multirow{2}{*}{ MUNICIPIO } & \multicolumn{2}{|c|}{ Álvaro Uribe Vélez } & \multicolumn{2}{|c|}{ Horacio Serpa } & Luis Garzón & Carlos Gaviria \\
\hline & 2002 & 2006 & 2002 & 2006 & 2002 & 2006 \\
\hline Total Nacional & 5.862 .655 & 7.397 .835 & 3.514 .779 & 2.613 .157 & 680.245 & 1.404 .235 \\
\hline Total Risaralda & 191.141 & 210.738 & 39.088 & 20.418 & 14.784 & 47.663 \\
\hline Pereira & 104.727 & 110.508 & 20,326 & 10.065 & 8485 & 25.869 \\
\hline Apia & 3,023 & 4.057 & 242 & 149 & 119 & 491 \\
\hline Balboa & 1,031 & 1.355 & 1141 & 636 & 107 & 253 \\
\hline Belén de Umbría & 5.547 & 6.983 & 506 & 358 & 492 & 1.092 \\
\hline Dosquebradas & 36,718 & 40.848 & 6177 & 3.392 & 3016 & 8.670 \\
\hline Guática & 2,284 & 2.951 & 396 & 575 & 251 & 217 \\
\hline La Celia & 1480 & 2.097 & 295 & 81 & 127 & 370 \\
\hline La Virginia & 7510 & 7.647 & 2060 & 1.061 & 557 & 2.298 \\
\hline Marsella & 4,321 & 4.639 & 1451 & 520 & 317 & 933 \\
\hline Mistrató & 1,011 & 1.266 & 377 & 157 & 187 & 677 \\
\hline Pueblo Rico & 533 & 1.060 & 124 & 100 & 68 & 472 \\
\hline Quinchía & 1,216 & 2.979 & 3636 & 2.640 & 287 & 1.794 \\
\hline Santa rosa & 18,376 & 20.643 & 2064 & 882 & 924 & 3.448 \\
\hline Santuario & 3,364 & 3.705 & 293 & 160 & 189 & 721 \\
\hline
\end{tabular}

\footnotetext{
${ }^{13} \mathrm{Al}$ igual que los senadores electos de todos los partidos que habían sido víctimas de expulsiones o de rechazos en la campaña.
} 
Quinchia fue el único municipio donde el candidato Presidente no sobrepasó el $50 \%$, quizás porque a comienzos de la primera administración Uribe, la Fiscalía detuvo más de 100 dirigentes de esta localidad, incluyendo el alcalde electo y varios concejales. Transcurridos más de dos años no se aportaron las pruebas suficientes y estas personas debieron ser puestas en libertad.

\section{Votación por Horacio Serpa}

El candidato del partido Liberal, contra toda previsión, sólo sumó 20.418 votos en este departamento con claras tradiciones liberales y que venía de aportar en las elecciones de Congreso una curul en el Senado y dos en la Cámara de Representantes habiéndose mantenido como la fuerza política mayoritaria.

La debacle de la candidatura de Serpa en Risaralda no se explica sólo por falencias estructurales de su campaña a nivel nacional. A estas razones debe agregarse la literal orfandad en la que quedó su aspiración, dado que la gran mayoría de dirigentes liberales no activaron sus organizaciones proselitistas; otros hicieron mutis por el foro y otros más fueron a parar decididamente a las campañas del uribismo o del PDA. Sorprendió la conducta de Rodrigo Rivera, quien venía de conquistar más de 500 mil votos en la consulta del liberalismo y quien había salido electo Senador en 2002 con una de las más altas votaciones del país. Este dirigente prefirió "quedarse quieto" y difícilmente se le vio en actos públicos con el candidato oficial de su Partido.

Así pues, la aspiración de Serpa nunca pudo arrancar en firme ni contó con la dinámica partidista liberal, lo cual solo causó extrañeza, pues a su favor jugaba la jefatura única del Partido Liberal en manos de César Gaviria y el nombramiento de Iván Marulanda como su fórmula vicepresidencial, ambos oriundos de estas tierras.

\section{El apoyo a Carlos Gaviria}

En Risaralda el ambiente político electoral en las toldas liberales contrastó, también, con el que se vivió en el PDA en donde, a pesar de sus diferencias internas, todos los dirigentes trabajaron de la mano de Carlos Gaviria para fortalecer su candidatura. Esta organización política no tenía en 2006 representación en los Concejos ni en la Asamblea.

El candidato del PDA superó ampliamente lo obtenido por Luis Eduardo Garzón (15 mil votos) en 2002 y pasó las metas que se había impuesto ${ }^{14}$ la Dirección Nacional de ese partido y consiguió alrededor de 48 mil sufragios.

A escala municipal, sobresalen Quinchía, Mistrató y Pueblo Rico, en los que, no obstante su pequeña población electoral, Carlos Gaviria sumó casi un tercio de la votación. Estas son localidades de presencia de comunidades indígenas y afro colombianas en las que se ha vivido durante años la presencia del conflicto armado. En los municipios metropolitanos y más urbanizados (Pereira, Dosquebradas, La Virginia) la votación por el candidato del PDA participó, en promedio, con el 18\%. En estos tres municipios existe un histórico predominio electoral del partido Liberal.

\footnotetext{
${ }^{14}$ En una circular interna fijando las metas departamentales, la dirección nacional del PDA estimaban que en la primera vuelta presidencial obtendrían 2.267.000 votos, de los cuales 40 mil serían aportados por Risaralda (además esperaban 40 mil en Caldas, 36 mil Quindío, 270 mil en el Valle y 90 mil en el Tolima).
} 
También debe destacarse el caso de Santa Rosa, la única localidad en la que el PDA hacía parte de la coalición de Gobierno. Allí se esperaba una votación mucho mayor y Gaviria sólo logró sumar el $13 \%$ del electorado. Esto sugiere que los votantes que habían elegido para alcaldía una opción ajena al partido Conservador, regresaron a respaldar una candidatura más acorde con su tradición, lo cual confirma la efectiva distancia que media entre las campañas nacionales y las elecciones locales. En los demás municipios, el apoyo ciudadano a la candidatura de Carlos Gaviria osciló entre el 10\% de Apia o Balboa y el 14\% de Guática o Santuario.

Mapa 2. Municipios en los cuales la suma de los votos de Horacio Serpa y Nohemí Sanin fue superior con respecto al 51\% a los de Álvaro Uribe. 2006 


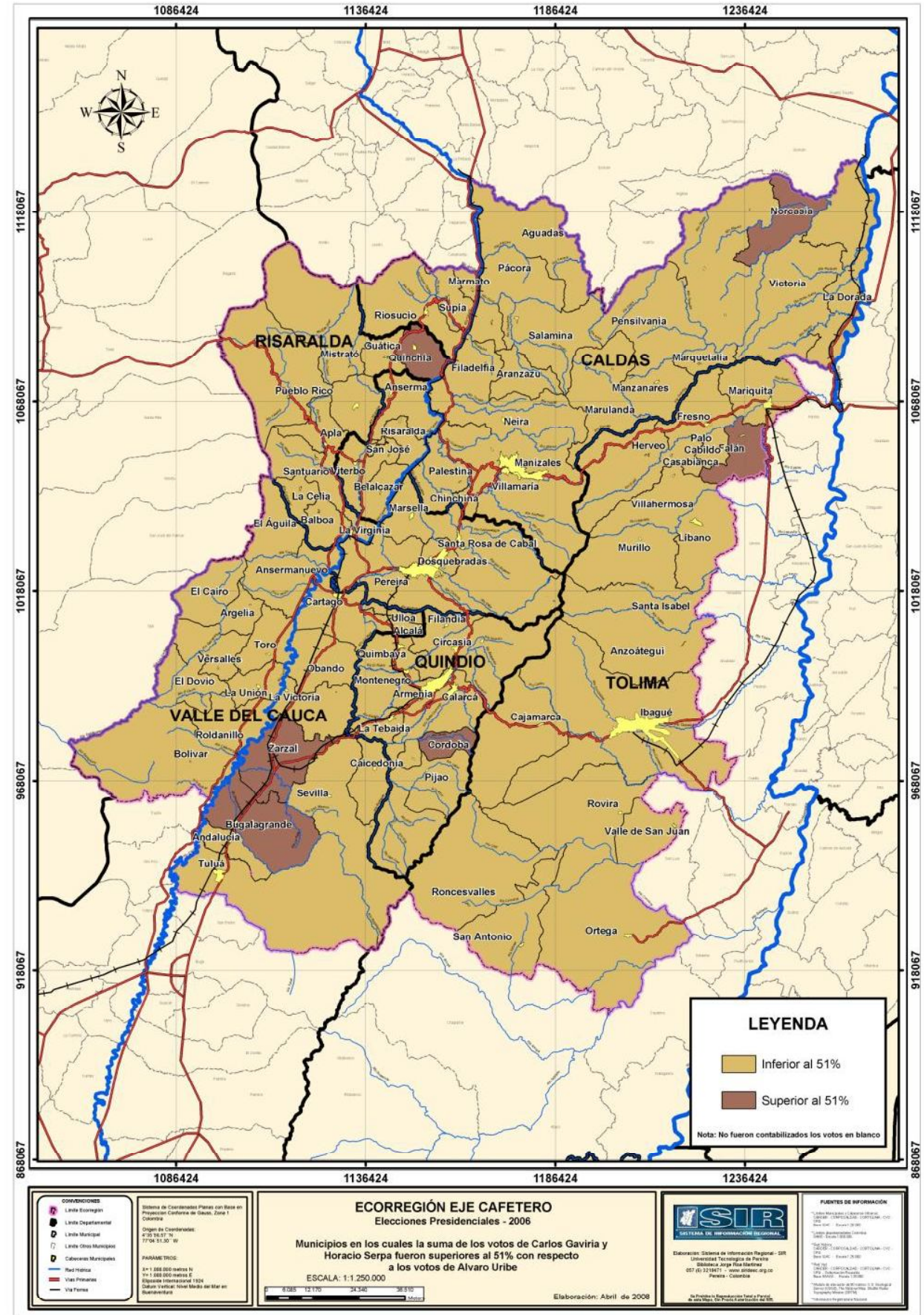

\section{De las elecciones presidenciales al nuevo mapa político.}

En Colombia se está transitando de un multipartidismo desbordado a un pluripartidismo limitado en el que las eventuales alianzas y coaliciones no terminan de configurarse. Este es un proceso que tenía sus propios retos, tanto para definir la actitud política frente a los proyectos del Gobierno, como para reagruparse de cara a las elecciones locales. 
El Presidente inició su segundo mandato nombrando como ministros a activos dirigentes partidistas. Por ejemplo, Carlos Holguín al Ministerio del Interior, Juan Lozano al de Ambiente, Vivienda y Desarrollo Territorial o Juan Manuel Santos al de Defensa.

Las elecciones (de Congreso y de Presidente) en 2006 generaron pues nuevas realidades políticas en Risaralda y confirmaron otras tantas. Se ratificó, en primer lugar, la habilidad del Alcalde de Pereira, Juan Manuel Arango, para moverse simultáneamente con amigos entre las filas del uribismo y de la campaña de Horacio Serpa. Se evidenció, en segundo lugar, una disposición del electorado a respaldar la segunda candidatura del Presidente Uribe más allá de las orientaciones partidistas. Se revalidaron, en tercer término, las claras distancias que existen entre las elecciones de alcance nacional, como las territoriales.

Varias de las dudas que aparecían en el análisis de la política risaraldense antes de las elecciones de 2007 se resumen así: el uribismo lograría consolidar alianzas regionales y presentaría candidatos únicos a alcaldías y gobernación? Aceptaría la pública vinculación de Colombia Viva? Qué mecanismo adoptaría para la selección de los aspirantes? Las fuerzas uribistas tomarían efectiva distancia del alcalde de Pereira? Qué sucedería con el movimiento Cambio Radical? Podría el Partido Conservador mantener cohesionados a sus dirigentes? El PDA presentaría listas propias a los Concejos y a la Asamblea? Cómo actuaría frente a la elección de Alcaldes y Gobernador? El Partido Liberal, en fin, saldría cohesionado con proyectos y candidatos propios? Seleccionaría sus candidatos a Alcaldías y Gobernación mediante la consulta interna?

\section{RISARALDA 2007: la reconfiguración política.}

En las elecciones de 2007 en el país se tuvo un notable aumento en la participación ciudadana: $30 \%$ frente a las elecciones del 2003 para alcaldía, un 20\% las de Concejo, un $21 \%$ las de Gobernaciones y en un 19\% las de Asambleas Departamentales.

En 2007, y contando con una votación global muy superior a la obtenida en las dos últimas elecciones territoriales, puede decirse que el uribismo (incluye los partidos de la U, Conservador, Cambio Radical, Convergencia Ciudadana, Apertura Liberal, Colombia Democrática) perdió en Bogotá pero conservó sus mayorías en el resto del país.

Por su parte, es verdad que el liberalismo sumó votos frente a los resultados de 2003, pero perdió espacios políticos significativos: pasó de 12 a 6 gobernaciones y de 228 a 206 alcaldías ${ }^{15}$.

\footnotetext{
${ }^{15}$ César Gaviria, jefe único del Partido Liberal evaluó de esta manera los resultados: "El poder regional lo perdimos en 2004, cuando los parlamentarios se comprometieron a votar por Uribe. Entonces ya no teníamos 14 gobernaciones sino tres, y ya no teníamos 29 senadores sino 15. ¿Qué tenemos ahora para mostrar? Que somos la primera fuerza política en el país, por un margen nada estrecho. En algunos departamentos tuvimos resultados extraordinarios, como la elección de Verano, la de Serpa, la de Andrés González. En torno a varios candidatos liberales se hicieron coaliciones muy grandes que llevaron a que el partido sea otra vez relevante. Obviamente perdimos en algunas partes, pero ganamos alcaldías, diputados, concejales. No niego que habríamos querido volver a ser un partido de cinco millones de votos, pero es claro que nos estamos recuperando bien. Obtuvimos cerca de 2.300 .000 votos, frente a 1.500 .000 en las elecciones parlamentarias.

"Sacamos 103 diputados; Ios conservadores, 79; La U, 59. Nuestro triunfo es claro, pero acepto que no es arrollador. Nadie barrió en las elecciones. Me habría gustado que ganáramos más gobernaciones". El Tiempo 30/10/07
} 
Tabla 9. Colombia. Resultados de elecciones territoriales por partidos. 2003-2007

\begin{tabular}{|l|r|r|r|r|r|r|r|r|}
\hline \multirow{2}{*}{ Partido } & \multicolumn{2}{|c|}{ Gobernaciones } & \multicolumn{2}{c|}{ Diputados } & \multicolumn{2}{c|}{ Alcaldes } & \multicolumn{2}{c|}{ Concejales } \\
\cline { 2 - 9 } & $\mathbf{2 0 0 3}$ & $\mathbf{2 0 0 7}$ & $\mathbf{2 0 0 3}$ & $\mathbf{2 0 0 7}$ & $\mathbf{2 0 0 3}$ & $\mathbf{2 0 0 7}$ & $\mathbf{2 0 0 3}$ & $\mathbf{2 0 0 7}$ \\
\hline Total & $\mathbf{3 2}$ & $\mathbf{3 2}$ & 598 & $\mathbf{5 2 0}$ & 1098 & 1099 & 12245 & 12.030 \\
\hline Liberal & 12 & 6 & 124 & 103 & 228 & 206 & 2777 & 2.265 \\
\hline Conservador & 4 & 5 & 60 & 76 & 158 & 240 & 1992 & 2.156 \\
\hline Partido de la U & & 7 & & 59 & & 123 & & 1.359 \\
\hline Cambio Radical & 2 & 3 & 11 & 48 & 25 & 112 & 466 & 1.292 \\
\hline PDA & & 1 & & 22 & & 20 & & 380 \\
\hline Otros & 14 & 10 & 403 & 212 & 387 & 398 & 7010 & 4578 \\
\hline
\end{tabular}

*: Solo se incluyen los datos de los cinco partidos mayoritarios

Fuente: 2003 con base en PNUD revista Hechos del Callejón. Septiembre, 2007. Para 2007, Registraduría Nacional.

Los cinco principales partidos en el país, son el Liberal, la U, el Conservador, Cambio Radical y el Polo Democrático Alternativo. Entre el partido de la U, el Conservador y Cambio Radical suman 4.807 concejales, 475 alcaldías, 183 diputados y casi la mitad de las gobernaciones.. La información confirma la débil presencia territorial tanto del PDA como del Partido Verde Opción Centro. Si bien es cierto que el PDA ganó en Bogotá y Nariño, su presencia en el resto del país evidencia un estancamiento dado que en 2003 había obtenido 19 alcaldías (si se suman las 17 del Polo Democrático Independiente y las del Frente Social y Político) y ahora obtuvo 20. La mitad de la votación del PDA estuvo en Bogotá.

El movimiento Alas Equipo Colombia, no obstante sus dificultades con la parapolítica, consiguió casi mil concejales, 83 alcaldías, 18 diputados y estará al frente de la gobernación de Antioquia.

Los partidos más vinculados al fenómeno de la parapolítica, esto es, Alas Equipo Colombia, Convergencia Ciudadana, Apertura Liberal, Colombia Democrática y Colombia Viva eligieron 239 Alcaldes, esto es, una quinta parte del total de las alcaldías en el país. Sin embargo, perdieron en gobernaciones que fueron claves para la articulación del proceso de expansión paramilitar como los departamentos de Santander, Cesar y Norte de Santander.

El ganador numérico fue el partido Conservador con 240 Alcaldías, seguido del partido Liberal con 206 Alcaldías. Atrás quedaron los resultados de las primeras elecciones de alcaldes en 1988 cuando el partido Liberal logró 446 Alcaldías y el Conservador obtuvo 413 Alcaldías

Sin embargo, otra lectura de las cifras indica que quien más ganancias tuvo en las elecciones de 2007 fue el Partido de la U. que se presentó por primera vez a elecciones locales y se constituyó en la tercera fuerza, pero además se convirtió en el principal heredero de aquellos movimientos políticos que tuvieron un buen número de Alcaldías y que desaparecieron en las elecciones de 2003. Movimientos como Moral, Convergencia Popular Cívica, Si Colombia, Mipol, Movimiento Popular Unido tuvieron en aquellas elecciones 102 alcaldías.

Dada la presencia política de múltiples movimientos avalados por firmas de ciudadanos en esta ocasión volvió a presentarse el fenómeno de la fragmentación política. 117 alcaldías fueron conseguidas por candidatos de estos movimientos. 
En síntesis, puede afirmarse que "el voto de opinión en las grandes ciudades del país está en los candidatos independientes, en ciudades intermedias siguen siendo importantes los votos liberal y conservador. Éste último sigue teniendo gran importancia en municipios pequeños y medianos"16.

Risaralda es un departamento de un millón de habitantes y 14 municipios, cuatro de los cuales (Pereira, Dosquebradas, Santa Rosa y La Virginia) aportan el 75\% del total de la población. Hasta 2002, prácticamente todo el control político estuvo en manos de los partidos Liberal y Conservador, pero con la elección de Álvaro Uribe, se presentó una reconfiguración política y de las filas liberales y conservadoras aparecieron los partidos afectos a su doctrina. La oposición históricamente estuvo representada en el Partido Comunista, el MOIR y la Unión Patriótica.

En las elecciones de 2007 no se presentaron asesinatos o atentados contra candidatos ni contra sedes de partidos políticos. Si existió, la presencia de la parapolítica recorrió caminos muy discretos y consiguió camuflarse adecuadamente. Entre la ciudadanía quedó la sensación de campañas que superaron, con mucho, los topes de financiación sin la respectiva claridad sobre sus fuentes.

En esta campaña hubo muchos factores en juego, pero quizás el que mayor interés público tuvo se relacionó con la decisión de César Gaviria como jefe único del partido Liberal de entregar avales, bajo su responsabilidad política, a las candidaturas de la Gobernación y de Pereira. La prensa nacional alcanzó a destacar este episodio como una confrontación en la que el expresidente apostaba parte importante de su prestigio.

\section{GOBERNACIÓN}

En las elecciones para Gobernación participaron 355 mil electores, cifra muy superior a la de 2003, cuando sólo intervinieron 274 mil ciudadanos. Se pasó de una abstención del 52\% a una del 44\%. En 2007 se contabilizaron 64 mil votos en blanco, nulos o tarjetas no marcadas.

La Gobernación de Risaralda que el liberalismo había reconquistado en 2003, a partir de 2008 queda en manos de Víctor Manuel Tamayo, un reconocido dirigente del partido Conservador que hizo una alianza con el partido de la $U$, con Colombia Viva y otros grupos menores. Mediante este acuerdo consiguió la cifra de 152 mil votos, la más alta en la historia departamental.

La campaña de Víctor Tamayo se impuso en 9 de los 14 municipios. Sorprendió su triunfo en Pereira, Desquebradas y La Virginia (es decir en el territorio del Area Metropolitana Centro Occidente) pues se trata de municipios donde históricamente el partido Liberal ha tenido mayorías y, como se explica más adelante, continúa siendo el partido que más votantes aporta para Asamblea o Concejos. Aquí se trata, entonces, de una decisión del electorado que se situó en contravía a las orientaciones formales de los dirigentes liberales.

El caso de Santa Rosa es atípico, pues se trata del municipio de origen del Gobernador Tamayo. Allí consiguió 16 mil votos, frente a 7 mil de Germán chica, su inmediato competidor.

${ }^{16}$ SANTANA, Pedro. En Caja de Herramientas. Noviembre, 2007 
También llamaron la atención los resultados en localidades de amplia tradición conservadora pero donde perdió la campaña de Víctor Tamayo. Estos fueron los casos de Belén, Guática, o Santuario.

Por expresa orientación de su jefe único, César Gaviria, el partido Liberal, que en Risaralda venía de una insoluble confrontación entre los precandidatos Germán Darío Saldarriaga y Mario Marín, avaló a Germán Chica como su candidato y obtuvo 121 mil votos. Este resultado incluye los votos aportados por el Partido Verde Opción Centro -PVOC y por Cambio Radical, fuerzas políticas que estuvieron a favor de esta candidatura liberal. Se destaca que los votos obtenidos por el candidato Chica superaron en 31 mil los 88 mil sufragios conseguidos por la lista oficial del liberalismo para la Asamblea.

Tabla 10. Risaralda. Elecciones para Gobernador, según municipio. 2007

\begin{tabular}{|l|r|r|r|r|r|r|r|r|}
\hline \multicolumn{1}{|c|}{ CANDIDATO } & TOTAL & PEREIRA & APIA & BALBOA & $\begin{array}{c}\text { BELEN DE } \\
\text { UMBRIA }\end{array}$ & DOSQ/DAS & GUATICA & $\begin{array}{r}\text { LA } \\
\text { CELIA }\end{array}$ \\
\hline $\begin{array}{l}\text { Víctor Manuel } \\
\text { Tamayo }\end{array}$ & 152,496 & 76,091 & 3,037 & 638 & 3,331 & 27,346 & 2,165 & 1,731 \\
\hline German Chica & 121,533 & 56,363 & 1,909 & 1,909 & 6,045 & 23,990 & 3,523 & 1,364 \\
\hline Gonzalo Arango & 11,305 & 6,896 & 86 & 72 & 132 & 2,208 & 61 & 85 \\
\hline Juan Carlos Grillo & 5,833 & 4,005 & 30 & 15 & 49 & 941 & 40 & 17 \\
\hline Votos Por Candidatos & 291,167 & 143,355 & 5,731 & 2,634 & 9,557 & 54,485 & 5,789 & 3,197 \\
\hline Votos En Blanco & 23,311 & 14,006 & 121 & 76 & 279 & 5,706 & 105 & 61 \\
\hline Votos Nulos & 8,769 & 4,380 & 90 & 68 & 257 & 2,260 & 82 & 75 \\
\hline Votos No Marcados & 31,605 & 14,597 & 380 & 322 & 882 & 6,719 & 534 & 320 \\
\hline TOTAL VOTOS & 354,852 & 176,338 & 6,322 & 3,100 & 10,975 & 69,170 & 6,510 & 3,653 \\
\hline & & & & & & SANTA & & ROSA DE \\
CA CANDIDATO & VIRGINIA & MARSELLA & MISTRATO & RICO & QUINCHIA & SANTUARIO \\
\hline Víctor Manuel & 7,440 & 3,561 & 2,766 & 2,093 & 4,332 & 15,884 & 2,081 \\
Tamayo & 5,192 & 2,955 & 1,464 & 991 & 5,528 & 6,815 & 2,816 \\
\hline Germán Chica & 446 & 126 & 71 & 53 & 503 & 466 & & 100 \\
\hline Gonzalo Arango & 112 & 56 & 15 & 33 & 210 & 259 & 51 \\
\hline Juan Carlos Grillo & 13,19 & 6,698 & 4,316 & 3,17 & 10,573 & 23,424 & 5,048 \\
\hline Votos Por Candidatos & 777 & 357 & 60 & 80 & 259 & 1,23 & & 194 \\
\hline Votos En Blanco & 284 & 155 & 90 & 68 & 237 & 565 & 158 \\
\hline Votos Nulos & 1,425 & 1,032 & 721 & 937 & 928 & 2,144 & 664 \\
\hline Votos No Marcados & 15,673 & 8,242 & 5,187 & 4,255 & 11,997 & 27,363 & & 6,064 \\
\hline Total Votos & & & & & &
\end{tabular}

Fuente: Registraduría Nacional

El Polo Democrático Alternativo -PDA, tuvo como candidato al dirigente profesoral Gonzalo Arango y consiguió el apoyo de 11 mil electores, cuando la lista oficial para la Asamblea sumó un poco más de 14 mil sufragios.

Juan Carlos grillo, el cuarto candidato, quien estuvo en un alto cargo del gobierno nacional entre 2003 y 2007, presentó su nombre apoyado en firmas de ciudadanos y obtuvo cerca de 6 mil votos. 


\section{ASAMBLEA RISARALDA.}

Los votos por las 12 curules de la Asamblea representan la cifra más aproximada de la realidad política risaraldense, pues aquí los partidos se contabilizan a través de sus listas únicas. Para la duma, tal como sucedió a nivel nacional, el primer factor a destacar se relaciona con el crecimiento del número de votantes, pues se superaron todos los cálculos y 376 mil ciudadanos se acercaron a las urnas, frente a 276 mil electores en 2003. Se disminuyó la abstención del $52 \%$ al $41 \%$.

Tabla 11. Risaralda. Votos por Asamblea, según partido y curules obtenidas. 2007

\begin{tabular}{|l|r|r|}
\hline \multicolumn{1}{|c|}{ Votos y Partido } & \multicolumn{1}{c|}{ Asamblea } & \multicolumn{1}{c|}{ Curules } \\
\hline Total & 376233 & \\
\hline En blanco & 36880 & \\
\hline Válidos & 318870 & \\
\hline Nulos & 22971 & \\
\hline No marcados & 34392 & \\
\hline \% participación & 59 & \\
\hline Votos por Asamblea & & \\
\hline Liberal & 87982 & \\
\hline Social de Unidad Nacional & 33503 & \\
\hline Colombia Viva & 49949 & \\
\hline Conservador & 51761 & \\
\hline MIRA & 19052 & \\
\hline Polo Democrático Alternativo & 14206 & \\
\hline Partido Verde-Opción Centro & 3641 & \\
\hline Cambio Radical & 17074 & \\
\hline Alianza Social Indígena & 4822 & \\
\hline
\end{tabular}

Fuente: Registraduría. Consulta en 30/10/07

Entre los votos en blanco (36 mil), nulos (22 mil) y las tarjetas no marcadas (34 mil) suman 92 mil los sufragios que terminaron por fuera de la competencia real. Una cifra significativa si se recuerda que termina representando el $25 \%$ de la votación total y que sobrepasa los votos del Partido Liberal a partir de los cuales esta organización consiguió cinco curules.

Tabla 12. Risaralda. Diputados según partido. 2003-2007.

\begin{tabular}{|c|c|c|}
\hline \multirow{2}{*}{ Partido } & \multicolumn{2}{|c|}{ Asamblea } \\
\hline & 2003 & 2007 \\
\hline Liberal & 6 & 5 \\
\hline Conservador & 3 & 3 \\
\hline Nuevo Partido & 2 & \\
\hline Colombia Viva & 1 & 2 \\
\hline MIRA & & 1 \\
\hline Social de Unidad Nacional & & 1 \\
\hline
\end{tabular}

Fuente: Registraduría. Consulta en 301007

La configuración política de la Asamblea sólo tuvo cambios de nomenclatura. El partido Liberal quedó con cinco diputados y tenía seis; El partido Conservador mantuvo su participación con tres curules; Colombia Viva obtuvo dos curules (la esposa del senador Habib Mehreg y la hija 
de la concejal Judith Giraldo ${ }^{17}$ ). El Partido de la U, que recogió el Nuevo Partido, solo consiguió un cupo, y el MIRA la curul restante. Repitieron curul 4 diputados y 8 llegaron por primera vez. Por fuera quedaron, entre otros, Cambio Radical, que consiguió 17 mil votos; el PDA con 14 mil y el PVOC con 11 mil.

Tabla 13. Risaralda. Votación por diputados electos según Partido. 2003-2007

\begin{tabular}{|c|c|c|c|c|c|}
\hline \multicolumn{3}{|c|}{2003} & \multicolumn{3}{|c|}{2007} \\
\hline NOMBRE & VOTOS & PARTIDO & NOMBRE & VOTOS & PARTIDO \\
\hline Ezequiel González & 7,374 & $\mathrm{CV}$ & & & \\
\hline Tulio Gallego & 2679 & & & & \\
\hline Carlos Torres & 5,637 & $\mathrm{PL}$ & Carlos Torres & 9710 & $\mathrm{PL}$ \\
\hline Hugo Arango & 4,444 & $\mathrm{PL}$ & & & \\
\hline Mario Marín & 6,970 & $\mathrm{PL}$ & Mario Marín & 7916 & $\mathrm{PL}$ \\
\hline James Alzate & 4,753 & $\mathrm{PL}$ & & & \\
\hline Atilano Córdoba & 6,465 & $\mathrm{PL}$ & & & \\
\hline Martha Montes & 4,330 & $\mathrm{PC}$ & & & \\
\hline Nelson Palacio & 4,881 & $\mathrm{PC}$ & & & \\
\hline Cesar Franco & 3,573 & $\mathrm{PC}$ & Cesar Franco & 4348 & $\mathrm{PC}$ \\
\hline Jhon Jairo Santa & 6,231 & NP & & & \\
\hline Enrique Vásquez & 5,120 & $\mathrm{NP}$ & Enrique Vásquez & 6831 & $\mathrm{PU}$ \\
\hline & & & Ancizar Duque & 5778 & $\mathrm{PL}$ \\
\hline & & & Luis E Saldariaga & 5625 & $\mathrm{PL}$ \\
\hline & & & Ernesto Zuluaga & 5334 & $\mathrm{PL}$ \\
\hline & & & Sigifredo Salazar & 5150 & $\mathrm{PC}$ \\
\hline & & & Julio Londoño & 4828 & $\mathrm{PC}$ \\
\hline & & & Claudia J Encizo & 11041 & CV \\
\hline & & & Elena Salazar & 5678 & $\mathrm{CV}$ \\
\hline & & & Marta Cecilia Alzate & 6025 & MIRA \\
\hline
\end{tabular}

Fuente: Registraduría. Consulta en 301007

PL: Partido Liberal; CV: Colombia Viva; PC: Partido Conservador; VC: Vamos Colombia; NP: Nuevo Partido; PU: Partido de la U.

Una vez más la configuración de la Asamblea quedará representada, en gran medida, por los candidatos que consiguieron la mayoría de su votación en Pereira, la capital del departamento. En efecto, ocho de los doce diputados salieron electos gracias básicamente al electorado pereirano. Diferentes a ellos, sólo llegarán a la duma diputados oriundos de Dosquebradas, Santa Rosa, Apía y Belén. Esta circunstancia obliga a salir en respaldo de iniciativas de reforma política que garanticen la presencia de la provincia en las Asambleas departamentales.

Finalmente, debe mencionarse que las listas de la coalición afecta (partidos Conservador, de la U y Colombia Viva) al gobernador electo sumaron 135 mil votos, 17 mil votos menos que el candidato triunfador, lo cual significa que se trató de un acuerdo político que efectivamente funcionó y que el desempeño práctico de la administración estará atado, en gran medida, a la permanencia de este pacto.

\footnotetext{
${ }^{17}$ Esta última inscribió su candidatura y obtuvo su curul a nombre del movimiento De corazón por Pereira.
} 


\section{ALCALDÍAS}

Ahora bien, las campañas electorales para las 14 alcaldías del departamento produjeron algunas sorpresas y confirmaron la mayoría de los pronósticos que habían anunciado diversas firmas encuestadoras.

El dato más relevante se relaciona con el partido Liberal, quien pasó de controlar seis alcaldías a sólo dos: Balboa y Belén de Umbría. El primero es un pequeño municipio de larga tradición liberal en donde hubo una consulta popular y candidato único. El segundo es una localidad en la que nunca el partido Conservador había perdido una elección.

El liberalismo perdió en esta oportunidad la dirección política de Dosquebradas (la segunda ciudad en población), Marsella, Mistrató y Quinchía. Si a ello se le suma que en 2003 el Nuevo Partido había tomado el control de Pereira, la ciudad capital, y que acaba de perder la Gobernación, es claro que la dirigencia liberal tendrá grandes retos en el inmediato futuro para recomponer sus fuerzas.

Tabla 14. Risaralda. Alcaldes según Partido. 2003-2007

\begin{tabular}{|l|r|r|}
\multicolumn{1}{c}{} & \multicolumn{2}{c|}{ Alcaldes } \\
\multicolumn{1}{c}{} & 2003 & \multicolumn{1}{c|}{2007} \\
\hline Liberal & 6 & 2 \\
\hline Conservador & 5 & 4 \\
\hline Nuevo Partido & 1 & \\
\hline Alas Equipo Colombia & & 1 \\
\hline Colombia Democrática & & 1 \\
\hline Apertura Liberal & & 1 \\
\hline Cívicos y coaliciones & 2 & 5 \\
\hline
\end{tabular}

El Partido Conservador mantuvo la alcaldía de Apía y recuperó las administraciones de Santa Rosa (el tercer municipio en población) que había perdido a manos de un movimiento cívico, y Mistrató, una localidad que controlaba el liberalismo.

En Pueblo Rico, municipio de compleja presencia multiétnica, se aplicó la estrategia de todos contra la candidatura de un dirigente indígena. Luego de una extraña consulta interpartidaria, finalmente triunfó el candidato de Apertura Liberal, un partido que en Risaralda no tuvo listas para Asamblea y sólo presentó listas para tres Concejos, pues las demás expectativas políticas del exrepresentante Octavio Carmona, su vocero, se tramitaron al interior de Colombia Viva. Por ejemplo, a nombre de ese movimiento inscribió la candidatura de su esposa para el Concejo de Pereira.

En Guática, un histórico municipio conservador, hubo un reacomodo y la alcaldía estará bajo la dirección de Alas Equipo Colombia, un partido prácticamente desconocido en el departamento. Algo similar sucedió en La Celia donde Colombia Democrática, obtuvo el triunfo sin tener otra forma de presencia seccional.

En los demás municipios, operó la estrategia de recolección de firmas y de franquicias electorales. En Dosquebradas, la alcaldesa electa se inscribió a nombre de de Dosquebradas digna, pero es un hecho que su campaña agrupaba todas las fuerzas uribistas; un caso similar se presentó Quinchía donde Alicia Palacios se inscribió a nombre del Movimiento Independiente. Lo propio sucedió en La Virginia y en Santuario. 
Mapa 3. Municipios en los cuales fueron elegidos alcaldes de partidos o movimientos de tendencia Uribista. 2003.

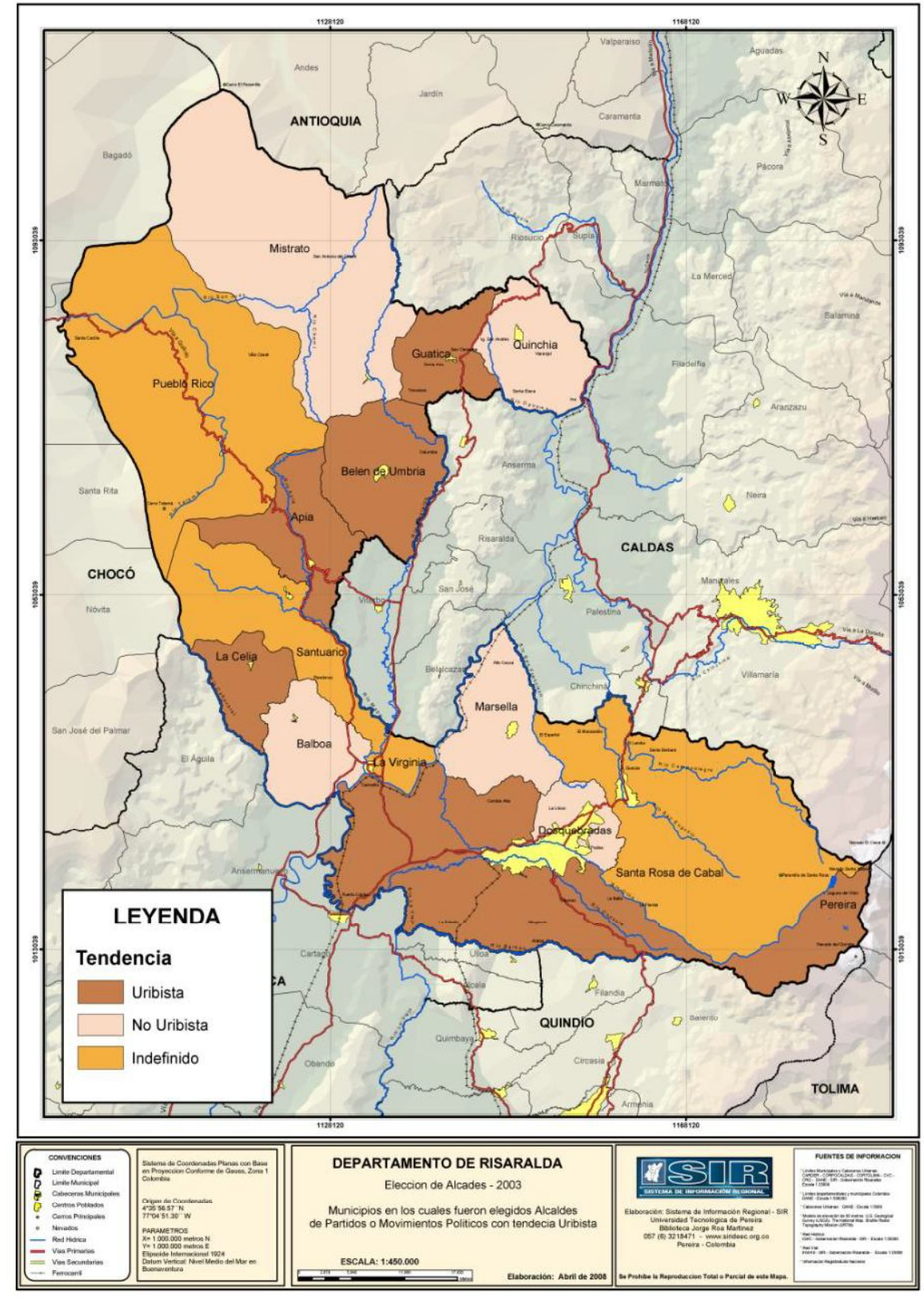


Mapa 4. Municipios en los cuales fueron elegidos alcaldes de partidos o movimientos de tendencia Uribista. 2007.

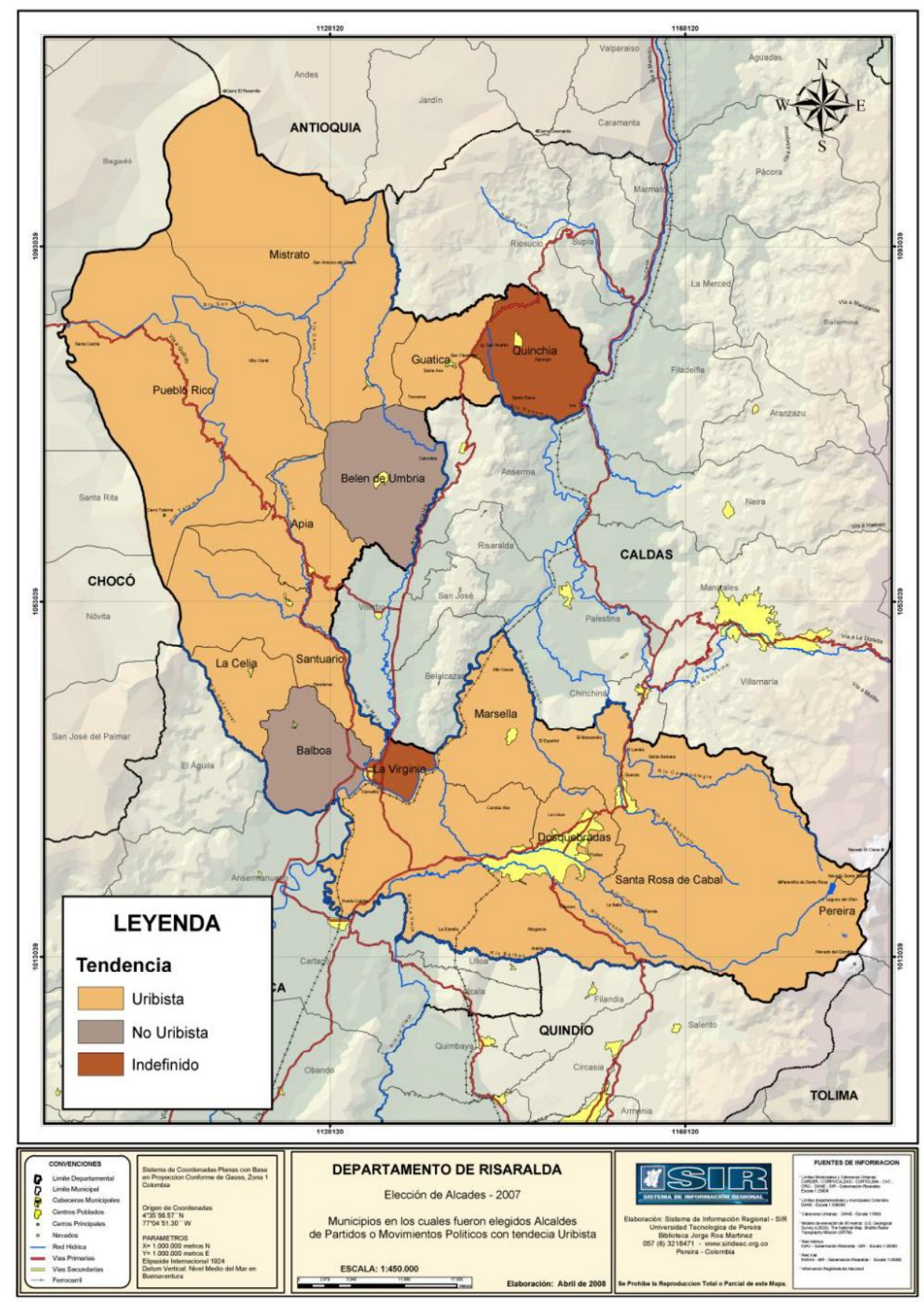

\section{CONCEJOS MUNICIPALES}

Sobre un total de 174 concejales, el partido Liberal con 62 y el partido Conservador con 47, continúan controlando de manera significativa los cabildos. Estos dos partidos son los únicos con representación en todos los concejos. Aunque ya se cuenta con la presencia de otras fuerzas y movimientos políticos, aún se presentan los casos de municipios cuyo cabildo es 
controlado hegemónicamente por uno o ambos partidos. Por ejemplo, en Balboa de 9 concejales, 8 son liberales y 1 es conservador ó en Belén de Umbría, municipio en el que 7 son concejales liberales y 6 son conservadores.

Tabla 15. Risaralda. Votos para concejos y concejales electos por partido. 2007

\begin{tabular}{|l|r|}
\hline \multicolumn{1}{|c|}{ VOTOS Y PARTIDO } & \multicolumn{1}{c|}{ TOTAL } \\
\hline Total & 383329 \\
\hline En blanco & 16613 \\
\hline Válidos & 338951 \\
\hline Nulos & 28257 \\
\hline No marcados & 16101 \\
\hline \% de participación & 61 \\
\hline & 62 \\
\hline Liberal & CONCEJALES \\
\hline Social de Unidad Nacional & 10 \\
\hline Colombia Viva & 11 \\
\hline Conservador & 47 \\
\hline MIRA & 3 \\
\hline Polo Democrático Alternativo & 1 \\
\hline Partido Verde-Opción Centro & 3 \\
\hline Cambio Radical & 4 \\
\hline Alianza Social Indígena & 6 \\
\hline Alas Equipo Colombia & 5 \\
\hline Colombia Democrática & 5 \\
\hline Convergencia Ciudadana & 2 \\
\hline Apertura Liberal & 8 \\
\hline Pereira Social & 2 \\
\hline Dosquebradas Social & 2 \\
\hline Ciudadanos por Marsella & 1 \\
\hline De corazón Por Pereira & 1 \\
\hline Unidos por Santuario & 3 \\
\hline
\end{tabular}

Colombia Viva, se colocó como la tercera fuerza al medir esta variable y obtuvo 11 concejales, así: 2 en Pereira, Dosquebradas y Santuario respectivamente; 1 en La Virginia y en Marsella, y 3 en Santa Rosa.

El partido de la $U$, muy por debajo de sus pronósticos, solo consiguió 10 concejales, de los cuales 3 en Pereira y 3 en Dosquebradas. En Apía, La Celia, La Virginia y Marsella obtuvo un escaño en cada municipio.

Debe destacarse, también, la presencia de Apertura Liberal, el movimiento dirigido por Octavio Carmona que finalmente, además de la Alcaldía de Pueblo Rico pudo lograr 3 concejales en este municipio y 5 curules en el cabildo de Quinchía $^{18}$.

\footnotetext{
${ }^{18}$ Municipio recordado, además de su pobreza, por haber sido víctima de una de las mayores redadas que conoció el país en el comienzo de la administración Uribe en 2002. Fueron detenidas 120 personas que luego, por falta absoluta de pruebas, debieron ser dejadas en libertad.
} 
Tabla 16. Risaralda. Votos para Concejos y concejales electos por partidos, según municipios. 2007

\begin{tabular}{|c|c|c|c|c|c|c|c|c|c|c|c|}
\hline \multirow[t]{2}{*}{ VOTOS Y PARTIDO } & \multicolumn{11}{|c|}{ MUNICIPIO } \\
\hline & Total & 1 & 2 & 3 & 4 & 5 & 6 & 7 & 8 & 9 & 10 \\
\hline Total & 383329 & 194133 & 6692 & 3226 & 11477 & 77257 & 6671 & 3974 & 15837 & 8138 & 5309 \\
\hline En blanco & 16613 & 9484 & 134 & 58 & 335 & 3910 & 91 & 63 & 469 & 217 & 66 \\
\hline Válidos & 338951 & 174144 & 5893 & 2769 & 9348 & 68603 & 5870 & 3322 & 13997 & 7247 & 4501 \\
\hline Nulos & 28257 & 13402 & 532 & 293 & 1174 & 5675 & 469 & 413 & 1195 & 502 & 461 \\
\hline No marcados & 16101 & 6587 & 267 & 164 & 935 & 2979 & 332 & 239 & 645 & 389 & 347 \\
\hline \% de participación & 61 & 59 & 67 & 58 & 61 & 64 & 69 & 68 & 58 & 56 & 61 \\
\hline \multicolumn{12}{|l|}{ PARTIDO } \\
\hline Liberal & 62 & 6 & 4 & 8 & 7 & 5 & 1 & 3 & 5 & 4 & 3 \\
\hline $\begin{array}{l}\text { Social de Unidad } \\
\text { Nacional }\end{array}$ & 10 & 3 & 1 & & & 3 & & 1 & 1 & 1 & \\
\hline Colombia Viva & 11 & 2 & & & & 2 & & & 1 & 1 & \\
\hline Conservador & 47 & 2 & 6 & 1 & 6 & 2 & 4 & 4 & 2 & 6 & $\underline{6}$ \\
\hline MIRA & 3 & 1 & & & & 1 & & & 1 & & \\
\hline $\begin{array}{l}\text { Polo Democrático } \\
\text { Alternativo }\end{array}$ & 1 & 1 & & & & & & & & & \\
\hline $\begin{array}{l}\text { Partido Verde-Opción } \\
\text { Centro }\end{array}$ & 3 & 1 & & & & & & 1 & 1 & & \\
\hline Cambio Radical & 4 & & & & & 1 & & & 2 & & \\
\hline Alianza Social Indígena & 6 & & & & & & & & & & 2 \\
\hline Alas Equipo Colombia & 5 & & & & & & 4 & & & & \\
\hline Colombia Democrática & 5 & & & & & 1 & 2 & & & & \\
\hline $\begin{array}{l}\text { Convergencia } \\
\text { Ciudadana }\end{array}$ & 2 & & & & & & & & & & \\
\hline Apertura Liberal & 8 & & & & & & & & & & \\
\hline Pereira Social & 2 & 2 & & & & & & & & & \\
\hline Dosquebradas Social & 2 & & & & & 2 & & & & & \\
\hline Ciudadanos por Marsella & 1 & & & & & & & & & 1 & \\
\hline De corazón Por Pereira & 1 & 1 & & & & & & & & & \\
\hline Unidos por Santuario & 3 & & & & & & & & & & \\
\hline
\end{tabular}




\begin{tabular}{|c|c|c|c|c|}
\hline \multirow[t]{2}{*}{ VOTOS Y PARTIDO } & \multicolumn{4}{|c|}{ MUNICIPIO } \\
\hline & 11 & 12 & 13 & 14 \\
\hline Total & 4174 & 11797 & 28592 & 6052 \\
\hline En blanco & 43 & 158 & 1378 & 207 \\
\hline Válidos & 3378 & 10098 & 24764 & 5017 \\
\hline Nulos & 389 & 1206 & 1983 & 563 \\
\hline No marcados & 407 & 493 & 1845 & 472 \\
\hline \% de participación & 55 & 66 & 58 & 53 \\
\hline \multicolumn{5}{|l|}{ PARTIDO } \\
\hline Liberal & 3 & 7 & 4 & 2 \\
\hline \multicolumn{5}{|l|}{ Social de Unidad Nacional } \\
\hline Colombia Viva & & & 3 & 2 \\
\hline Conservador & 2 & & 4 & 2 \\
\hline \multicolumn{5}{|l|}{ MIRA } \\
\hline \multicolumn{5}{|l|}{ Polo Democrático Alternativo } \\
\hline \multicolumn{5}{|l|}{ Partido Verde-Opción Centro } \\
\hline Cambio Radical & & & 1 & \\
\hline Alianza Social Indígena & 3 & 1 & & \\
\hline Alas Equipo Colombia & & & & 1 \\
\hline Colombia Democrática & & & 2 & \\
\hline Convergencia Ciudadana & & & 1 & 1 \\
\hline Apertura Liberal & 3 & 5 & & \\
\hline \multicolumn{5}{|l|}{ Pereira Social } \\
\hline \multicolumn{5}{|l|}{ Dosquebradas Social } \\
\hline \multicolumn{5}{|l|}{ Ciudadanos por Marsella } \\
\hline \multicolumn{5}{|l|}{ De corazón Por Pereira } \\
\hline Unidos por Santuario & & & & 3 \\
\hline
\end{tabular}

Fuente: con base en Regitraduría.

Las 26 curules restantes se distribuyeron entre 13 partidos y pequeños movimientos políticos, siempre locales. Esto hace que en Concejos como el de Pereira vayan a estar presentes 9 fuerzas políticas, en Dosquebradas 8, y 7 en La Virginia. En estos tres municipios atrás quedó el control bipartidista tradicional, lo cual no significa, necesariamente, un paso adelante en materia de la esencial función del control político a las autoridades municipales.

\section{PEREIRA}

\section{ALCALDÍA}

En Pereira la misma coalición política de la Gobernación terminó alzándose con el triunfo y el candidato del partido de la U, Israel Londoño, tuvo el respaldo de 90 mil electores, el 50\% de los votos válidos y la cifra más alta desde 1988, año que inauguró la elección popular de alcaldes. Trabajando una campaña cohesionada con la candidatura a Gobernación de Víctor Manuel Tamayo, destacando la Llave de oro y apoyándose en la circunstancia de una ciudad que en la campaña presidencial de 2006 le había aportado 110 mil votos a Alvaro Uribe, lo

mismo que en las fisuras de la campaña contraria, este dirigente, forjado en las filas del 
liberalismo, con tránsito por el Nuevo Partido, y ahora como vocero del partido de la U gobierna esta ciudad de 420 mil habitantes.

El partido Liberal tuvo como precandidato a Luis Fernando Baena pero, también por intervención directa de su director nacional, terminó avalando, sin explicaciones públicas, la candidatura de la exalcaldesa Martha Elena Bedoya que en una alianza con Cambio Radical y el Partido Verde Opción Centro alcanzó 41 mil votos. Esta dirigente, formada en las filas liberales, había decidido en 2004 acompañar la formación del partido de la U y luego de un fugaz tránsito allí había resuelto desplegar su aspiración contando con el movimiento Tejiendo Ciudadanía y recogiendo firmas. Al momento de evaluar los resultados, se habló de vacilaciones ideológicas de la candidata, pero simultáneamente, se cuestionó la deslealtad de varios dirigentes liberales reclamando el porqué los votos de las listas liberales para el Concejo no se habían traducido en apoyos a su candidatura. En fin, se habló de una candidata que sufrió permanentes acusaciones de mantener grandes distancias con los dirigentes que deseaban impulsar su campaña y, a la inversa, de una candidatura que no fraguó relaciones orgánicas con la dirigencia local del partido Liberal.

En el análisis de las cifras de Alcaldía se puede notar que las listas de Concejo inclinadas por la campaña de Israel Londoño sumaron 52 mil votos, mientras que, al contrario, las listas del acuerdo formal con Martha Elena Bedoya se acercaron a los 90 mil sufragios. En este último caso se trató, en consecuencia, de un pacto político que tuvo un grave corto circuito, y que Tejiendo Ciudadanía, Cambio Radical y el partido Liberal nunca pudieron hacer real campaña conjunta. También se observaron diversos desencuentros entre las campañas liberales de Alcaldía y de Gobernación. Fue un hecho de público conocimiento el que gran parte de los candidatos a la Asamblea y al Concejo por el partido Liberal terminaron respaldando la candidatura de las agrupaciones uribistas en Pereira.

A su turno, Fredy Arias, un exconcejal liberal, habiendo sumado el $80 \%$ del apoyo de la dirigencia local, se desempeñó como candidato del PDA y en una corta campaña recibió el respaldo de 9 mil ciudadanos.

Finalmente, debe recordarse que por primera vez en Pereira se presentó una campaña con seis candidatos. Los tres restantes fueron John Jairo Santa, quien se inscribió con firmas; Horacio Galeano quien obtuvo la franquicia de Convergencia Ciudadana y Hector Artunduaga quien se apoyó en la personería de la Alianza Social Indígena. Entre los tres solo sumaron el $8 \%$ de los votos.

\section{CONCEJO MUNICIPAL}

Para la conformación del cabildo municipal pereirano participaron 195 mil electores, 30 mil de los cuales votaron en blanco, en forma nula o no marcaron sus tarjetas. Entre 2003 y 2007 la abstención disminuyó considerablemente y pasó del $55 \%$ al $41 \%$. Los votos válidos se incrementaron de 109 mil a 174 mil.

Tabla 17. Pereira. Votos para Concejo, según partido y curules obtenidas. 2007

\begin{tabular}{|l|r|l|}
\hline \multicolumn{1}{|c|}{ VOTOS Y PARTIDO } & CONCEJO & CURULES \\
\hline Total & 194133 & \\
\hline En blanco & 9484 & \\
\hline Nulos & 13402 & \\
\hline Válidos & 174444 & \\
\hline
\end{tabular}




\begin{tabular}{|l|r|r|} 
No marcados & 6587 & \\
\hline \% de participación & 59 & \\
\hline Liberal & 42597 & 6 \\
\hline Social de Unidad Nacional & 25129 & 3 \\
\hline Pereira Social & 19381 & 2 \\
\hline Colombia Viva & 15999 & 2 \\
\hline Conservador & 15085 & 2 \\
\hline De corazón por Pereira & 9213 & 1 \\
\hline MIRA & 8404 & 1 \\
\hline Polo Democrático Alternativo & 8242 & 1 \\
\hline Partido Verde-Opción Centro & 6537 & 1 \\
\hline Cambio Radical & 5908 & \\
\hline Alas Equipo Colombia & 5155 & \\
\hline Alianza Social Indígena & 1544 & \\
\hline Colombia Democrática & 1215 & \\
\hline Afrocolombiano & 251 & \\
\hline
\end{tabular}

Fuente: Registraduría. Consulta en 30/10/07

Cuatro años atrás, cinco partidos copaban las 19 curules del Concejo, así: 7 eran liberales, 6 del Nuevo Partido (un desprendimiento del Partido Liberal), 3 de Colombia Viva (también con claro origen liberal), 2 de Vamos Colombia y uno por el conservatismo.

Tabla 18. Pereira. Composición del Concejo, según partido. 2003-2007

\begin{tabular}{|l|r|r|}
\hline \multicolumn{1}{|c|}{ PARTIDO } & \multicolumn{1}{|c|}{ 2003 } & \multicolumn{1}{c|}{$\mathbf{2 0 0 7}$} \\
\hline Liberal & 7 & 6 \\
\hline Nuevo Partido & 6 & 2 \\
\hline Colombia Viva & 3 & 2 \\
\hline Vamos Colombia & 2 & 3 \\
\hline Conservador & 1 & 2 \\
\hline Social de Unidad Nacional & & 1 \\
\hline Pereira Social & & 1 \\
\hline De corazón por Pereira & & 1 \\
\hline MIRA & & 1 \\
\hline Polo Democrático Alternativo & & \\
\hline Partido Verde-Opción Centro & & \\
\hline Fuente: Regstradura. Consuta & & \\
\hline
\end{tabular}

Fuente: Registraduría. Consulta en 30/10/07

Desde 2008 asisten al Concejo representantes de 9 partidos y movimientos: 6 liberales; 3 por el partido de la U; 2 por Colombia Viva; 2 conservadores; 2 por Pereira Social (considerada como una lista alterna del liberalismo). EI PDA, el MIRA y el PVOC llevarán un concejal cada uno. EI movimiento De corazón por Pereira, tendrá la concejal restante. A esta corporación llegan, por primera vez, 11 Concejales.

Si bien se presume que los 42 mil votos que median entre los 92 mil obtenidos por el alcalde electo y los 50 mil de las listas para Concejo de su coalición, provienen de electores liberales que no acataron la orientación oficial de respaldar a Martha Elena Bedoya, es claro que de allí emerge una capacidad de negociación que colocará a prueba la relativa independencia de Israel Londoño como alcalde frente a las aspiraciones que seguramente harán sentir dirigentes 
como el representante Enrique Soto por el Partido de la U, Habib Mehreg y Octavio Carmona por Colombia Viva, lo mismo que el exalcalde César Castillo.

Tabla 19. Pereira. Votación por concejales electos según Partido. 2003-2007

\begin{tabular}{|c|c|c|c|c|c|}
\hline \multicolumn{3}{|c|}{2003} & \multicolumn{3}{|c|}{2007} \\
\hline NOMBRE & VOTOS & PARTIDO & NOMBRE & VOTOS & PARTIDO \\
\hline AMANCIO QUEJADA & 989 & $\mathrm{CV}$ & & & \\
\hline Martin López & 1,061 & $\mathrm{CV}$ & & & \\
\hline Peterson Lopera & 1,645 & $\mathrm{CV}$ & Peterson Lopera & 3821 & $\mathrm{PL}$ \\
\hline Eduardo Cardona & 1,637 & $\mathrm{PL}$ & & & \\
\hline José Fredy Arias & 2,517 & $\mathrm{PL}$ & & & \\
\hline Hernando Arcila & 3,592 & $\overline{P L}$ & Hernando Arcila & 3156 & $\mathrm{PL}$ \\
\hline Diomedes Toro & 1,271 & $\mathrm{PL}$ & Diomedes Toro & 2733 & $\mathrm{PL}$ \\
\hline Héctor Artunduaga & 1,192 & $\mathrm{PL}$ & & & \\
\hline José Javier Quiceno & 1,982 & $\mathrm{PL}$ & & & \\
\hline Benicio Zuluaga & 1,382 & $\mathrm{PL}$ & & & \\
\hline Iván Naranjo & 1,233 & $\mathrm{PC}$ & Iván Naranjo & 2299 & $\mathrm{PC}$ \\
\hline Israel Londoño & 2,976 & NP & & & \\
\hline Oscar Del Río & 1,311 & NP & & & \\
\hline Dora Martínez & 2,097 & NP & & & \\
\hline Horacio Galeano & 1,569 & NP & & & \\
\hline Lucas Arbeláez & 1,572 & $\mathrm{NP}$ & & & \\
\hline Ancizar Duque & 1,503 & NP & & & \\
\hline Judith Giraldo & 2,992 & VC & Judith Giraldo & 3559 & DCPP \\
\hline Yesid Rozo & 594 & $\mathrm{VC}$ & Yesid Roso & 2561 & $\mathrm{PL}$ \\
\hline Votos Por Listas & 101064 & & Adolfo A. Carvajal & 1984 & $\mathrm{PS}$ \\
\hline & & & Juan C. Reinales & 1390 & $\mathrm{PS}$ \\
\hline & & & Alonso Molina & 2267 & $\mathrm{PL}$ \\
\hline & & & Juan Pablo Gallo & 2807 & $\mathrm{PL}$ \\
\hline & & & Juan De La Cruz & 1759 & $\mathrm{CV}$ \\
\hline & & & Vivian López & 1739 & $\mathrm{CV}$ \\
\hline & & & Álvaro Escobar & 1981 & PC \\
\hline & & & Milton Chávez & 1705 & $\mathrm{PU}$ \\
\hline & & & José Quintero & 3140 & $\mathrm{PU}$ \\
\hline & & & José Quiceno & 1362 & $\mathrm{PU}$ \\
\hline & & & Geovani Londoño & 2797 & MIRA \\
\hline & & & Rubén D Orozco & 1072 & PVOC \\
\hline & & & Fernando Arias & 696 & PDA \\
\hline & & & Votos Por Listas & 149354 & \\
\hline
\end{tabular}

Fuente: Registraduría. Consulta en 301007

PL: Partido Liberal; CV: Colombia Viva; PC: Partido Conservador; VC: Vamos Colombia; NP: Nuevo Partido; PS: Pereira Social; PU: Partido de la U; DECPP: De Corazón por Pereira;

PVOC: Partido Verde Opción Centro; PDA: Polo Democrático Alternativo

De esta manera, en Pereira existe no poca expectativa por lo que pueda suceder con la eventual coalición mayoritaria. Sobre el papel, 10 de los concejales electos podrían estar en el campo de la oposición. Pero esta es una ciudad sin tradición en este campo y es claro que será el partido Liberal, el PDA y los demás partidos que públicamente no participaron al lado de la 
campaña de Israel Londoño quienes definan si se trabaja en el esquema gobierno-oposición o si se mantiene el método de la 'oposición reflexiva' o la 'colaboración crítica'.

\section{JUNTAS ADMINISTRADORAS LOCALES.}

El análisis del mapa político electoral terminaría incompleto sin la evaluación de lo sucedido con la elección de las Juntas Administradoras Locales. En el departamento de Risaralda, además de Pereira, este instrumento de participación existe en La Celia, Belén de Umbría, Dosquebradas, Pereira y Santa Rosa.

Aunque las funciones legales de las JAL son bastante formales y en los años de existencia el balance general de su actuación en la ciudad deja más preguntas que respuestas, es claro que las campañas electorales municipales tienen en estos instrumentos una eficaz correa de transmisión para soportar las aspiraciones de candidatos a Alcaldía o al Concejo. El control político territorial de las comunas y corregimientos se transforma, sin duda, en un importante termómetro para indagar por la real correlación de fuerzas políticas en un momento determinado y para disponer de un indicador de gran credibilidad al momento de analizar la efectiva presencia de las organizaciones políticas en los barrios y veredas.

En las 19 comunas y en los 12 corregimientos de Pereira, por ejemplo, se eligieron 155 dirigentes de JALs, 5 por cada una de ellas. De este proceso participaron casi 100 mil ciudadanos, sin contar los que votaron en blanco, no marcaron su tarjeta electoral o lo hicieron equivocadamente.

En esta ocasión sorprendieron los altos niveles de participación ciudadana buscando intervenir en los asuntos de su territorio más cercano, esto es, sus comunas y corregimientos. En promedio participaron 63 de cada 100 ciudadanos inscritos.

El partido Liberal, el partido de la U. y Colombia Viva lograron la votación necesaria para conseguir, en su orden la elección de 69, 54 y 14 'comuneros', como se ha dado en llamar a estos portavoces políticos. Atrás quedó la época en la que la organización liberal obtenía el $80 \%$ o más de los comuneros de Pereira ${ }^{19}$. Ahora sus dirigentes deberán hacer mayores esfuerzos, no sólo para garantizar la sostenibilidad de la organización política propiamente dicha, sino que en varios casos estarán obligados a desplegar una mayor iniciativa para conseguir los aliados indispensables para sus respectivas propuestas..

El control mayoritario de 10 JALs correrá por cuenta del partido Liberal, mientras que el partido de la U estará al frente de 8 Juntas. Además, en 12 JALs sólo estarán esos dos partidos. Colombia Viva dirigirá una Junta Administradora. En los demás casos serán necesarias coaliciones. La comuna de mayor fragmentación es la Oriente, con cuatro partidos representados. Al contrario, en el corregimiento de Combia Alta el partido Liberal tendrá los 5 comuneros.

Los otros partidos (Conservador, MIRA, Verde Opción Centro. Alas Equipo Colombia, Colombia Democrática y Cambio Radical) sumaron, entre todos, 18 dirigentes. Llama la atención que el Polo Democrático Alternativo no se hubiera hecho el propósito real de conseguir participación en estos escenarios.

${ }^{19}$ Cfr. ARANGO, Oscar. Pereira, años 80. Funderalda, Pereira, 1989. 
Descartado por ahora un acuerdo entre el partido de la $U$ y Colombia Viva que aportaría 68 comuneros, contra los 69 del Partido Liberal, es claro que los 18 dirigentes de los demás Partidos serán quienes terminen definiendo el rumbo de la Asociación Municipal de JALs en el inmediato futuro.

Mapa 5. Juntas Administradoras Locales con participación mayoritaria de partidos o movimientos Uribistas. Pereira. 2007

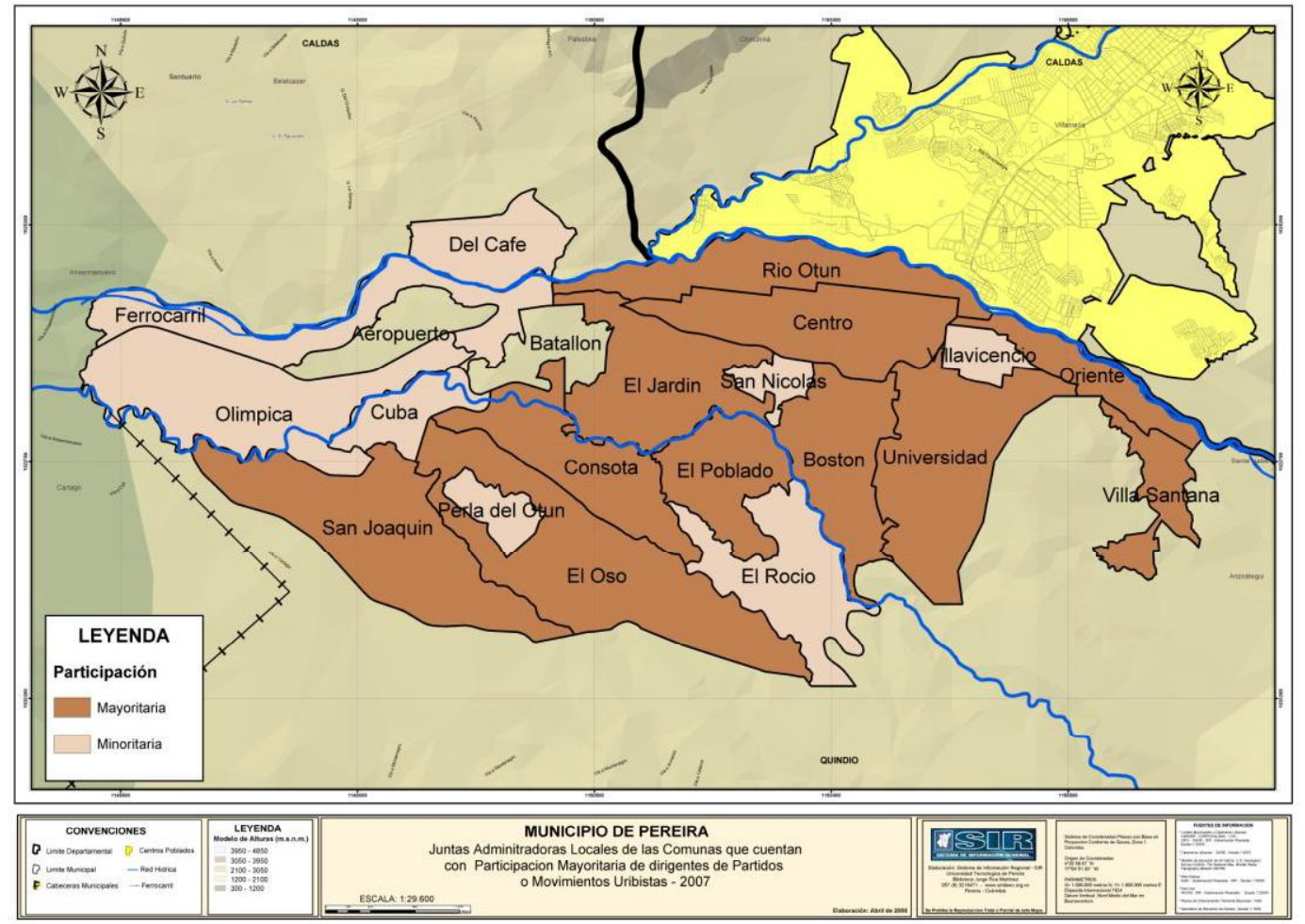

Mapa 6. Juntas Administradoras Locales de Corregimientos con participación mayoritaria de partidos o movimientos Uribistas. Pereira. 2007 


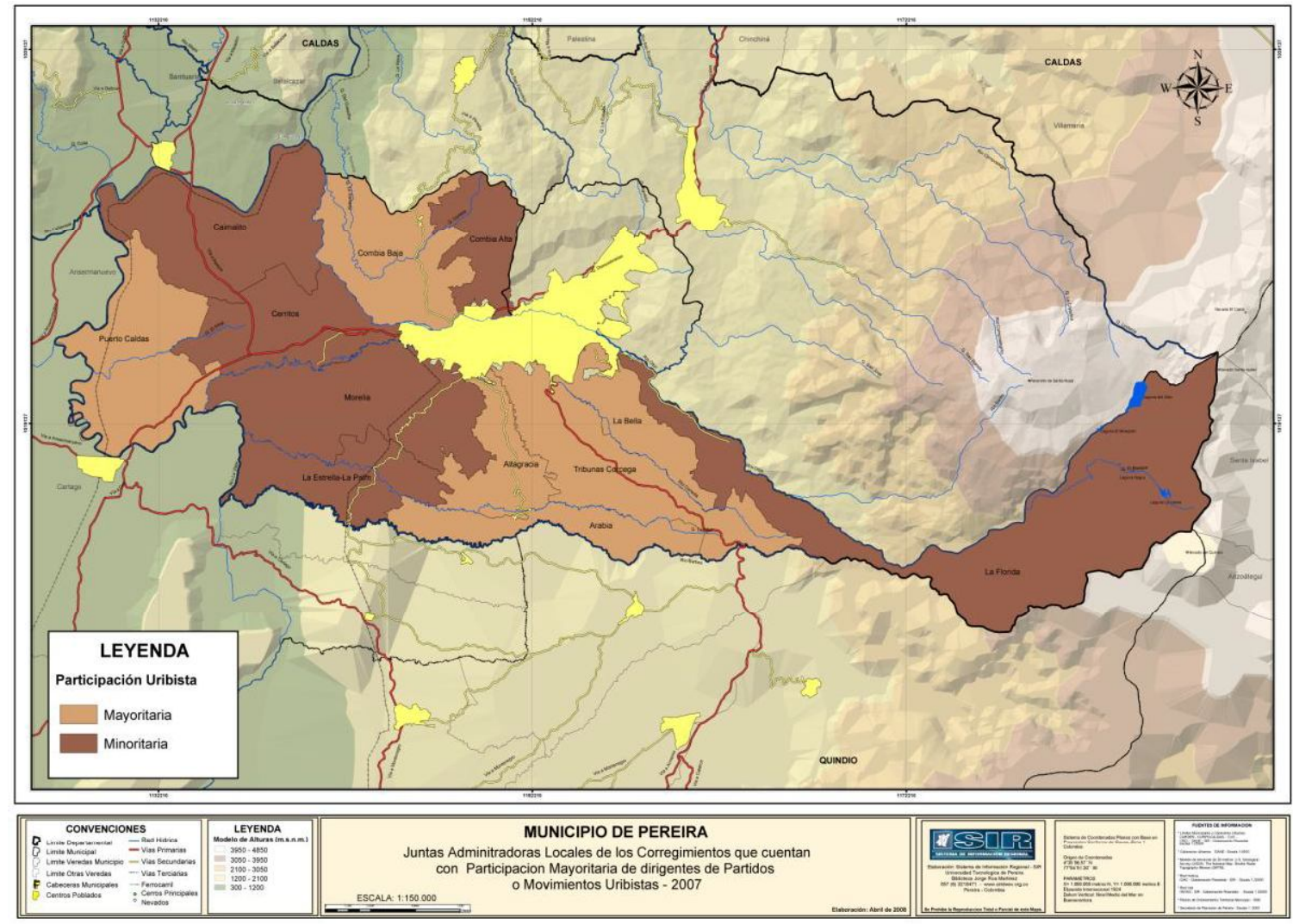

\section{LA DINÁMICA POSTELECTORAL.}

Quedan por resolver asuntos de cara a los desarrollos de la dinámica político partidista propiamente dicha. Está por conocerse la autoevaluación que los dirigentes regionales del PDA hayan producido sobre su desempeño político electoral y la forma como se articularán a los debates en curso acerca de cómo obtener nuevos y más amplios respaldos a escala local y departamental, pues en esta ocasión no superaron las cifras que en 2003 habían obtenido las organizaciones que sirvieron de fundamento a la creación de este partido en Risaralda. Tampoco son públicas aún las auto evaluaciones de Cambio Radical, del partido Liberal, del MIRA o del PVOC.

Adicionalmente, han surgido dudas de todo orden acerca de la dirigencia parlamentaria de Risaralda. El Representante conservador Diego Naranjo, perdió la alcaldía en Belén de Umbría, su municipio natal, y no tendrá un camino fácil para mantener su curul. Si bien es claro que el conservatismo contará con Gobernador de su partido, en el caso de Pereira aún no han definido cuál será la posición política, pues una parte de la colectividad acompañó la aspiración de Martha Elena Bedoya.

A su turno, los dos Representantes (Diego Patiño y Juan Carlos Valencia) y el Senador (Germán Aguirre) por el liberalismo, seguramente deberán contestar preguntas relacionadas con el resultado aquí descrito y que implican que, al tiempo de haber incrementado la votación, sufrieron la pérdida de la gobernación, varias alcaldías y diferentes curules en corporaciones públicas. Debe recordarse que para la Asamblea la lista de este Partido sumó 88 mil votos y 
para el Concejo de Pereira, al lado de la lista de Pereira Social ${ }^{20}$, contabilizó 62 mil sufragios. En este y en los otros partidos las aspiraciones al Congreso apenas empiezan a desbrozar su camino, pero desde ya se anuncian intensas confrontaciones internas.

Reconociendo que el partido de la U. sólo pudo elegir un diputado y 3 concejales en Pereira, el Representante Carlos Soto tendrá la tarea de hacer sostenible el acuerdo con Colombia Viva, un partido con serias dificultades internas pues sus dos principales dirigentes a nivel nacional están detenidos por parapolítica. Los intereses de estos actores personales, y la forma como tramiten sus tensiones, sin duda impactarán los gobiernos instalados el primero de enero de 2008.

También falta claridad, por ejemplo, acerca de si Juan Manuel Arango, exalcalde de Pereira, retornará oficialmente al partido Liberal para, desde allí, buscar una curul de Senado, lo cual obligaría a un claro replanteamiento en los cuadros directivos de esta colectividad. Y se busca información para conocer el rol que finalmente terminará desempeñando Germán Chica, un joven dirigente que por primera vez participó como candidato y logró superar la cifra que había obtenido el actual Gobernador.

Como se sabe, no existen campañas aisladas y toda elección está encadenada con la siguiente. Así, el desenlace de estos y otros debates irá despejando el camino para sopesar las fuerzas que intervendrán en las futuras campañas de Congreso y Presidencia. Aunque aún falta buen tiempo, lo que acaba de suceder conforma eslabones de gran importancia. Por ahora resulta claro que en Risaralda el factor cohesionador de las triunfantes campañas sigue representado en la figura de Alvaro Uribe y que, de no cristalizar una segunda reelección presidencial, se tendrían graves dificultades para obtener nuevos consensos entre quienes hoy permanecen formalmente unidos.

En fin, es de esperar que al iniciar las nuevas administraciones territoriales se evite el unanimismo en la gestión pública y se pueda configurar un sistema de pesos y contrapesos en el quehacer político, por una parte, y que el interés ciudadano se concentre en los programas que darán origen a los nuevos planes de desarrollo y que en ellos se privilegien los asuntos propios del desarrollo social para un departamento que, como Risaralda, mantiene elevados porcentajes de su población en condiciones de pobreza e indigencia, por la otra.

Una vez concluidas las elecciones, la dinámica política del país en todos sus frentes confirma que, efectivamente, los procesos democráticos trascienden, con mucho, la mecánica de los comicios. No existe democracia sin elecciones, pero estas son insuficientes para garantizar aquella.

\section{BIBLIOGRAFIA}

Actos legislativos: 1/2003 (reforma política); 2/2004 (reelección presidencial y participación en política de funcionarios públicos); 1/2004 (inhabilidades políticas para quienes hayan sido condenados por delitos contra el patrimonio del Estado); 2 y 3/2005 (reforma a la elección de la Cámara de Representantes); 1/2007 (moción de censura) y 4/2007 (composición del Concejo Distrital).

\footnotetext{
${ }^{20} \mathrm{La}$ inscripción de esta lista, que todos aceptan como de clara estirpe liberal se leyó, entre los observadores políticos, como una conducta desleal frente a la lista inscrita oficialmente a nombre del Partido Liberal. Algo similar sucedió en Dosquebradas. Experiencias de este tipo deben servir para hacer más rigurosa la norma sobre avales e inscripción de candidatos y listas.
} 
CEPEDA, Fernando. Financiación política y corrupción. Ariel. Bogotá, 2004

GUTIERREZ, Francisco. ¿Lo que el viento se llevó? Los partidos políticos y la democracia en Colombia. Norma. Bogotá, 2007-12-07

GTZ y otros. Campaña más mujeres, más política. Ganancias, límites y retos de las mujeres en el escenario político local: análisis de las elecciones del 28 de octubre de 2007. Separata en El Tiempo. Noviembre 30, 2007

Leyes: 892/2004 (nuevos mecanismos de votación e inscripción para garantizar el libre ejercicio de este derecho); 974/2005 (actuación en bancadas de los miembros de las corporaciones públicas); 996/05 (Garantías electorales); 1070/2006 (voto de extranjeros residentes en Colombia); 1134/2007 (concurso para elección del Registrador);

Misión de Observación Electoral. Informe nacional sobre las elecciones de 2007. En www.moe.org.co consulta en 15/12/07

NOVOA, Armando. La reforma política de 2003: menos partidos, ¿más democracia? En http://www3.terra.com.co/elecciones_2007/articulo/html/vbe206.htm

PNUD. Hechos del Callejón. Dossier Elecciones: todos con las pilas puestas. Septiembre, 2007 Proyecto de acto legislativo 252 de 2007. Reforma política

UNGAR, Elizabeth. No basta saber cómo Ilegaron, sino cómo actuaron. En Actualidad Colombiana. No. 447, marzo 12, 2007

Varios autores. La oposición política en Colombia. IEPRI-Fescol. Bogotá, 1996

Manizales, 2001

. Elecciones en el cambio de milenio. Cuatro estudios de caso. Alma Mater. 